UDK 784.15Filippo de Duc

Metoda Kokole

Muzikološki inštitut Znanstvenoraziskovalnega centra Slovenske akademije znanosti in umetnosti, Ljubljana Institute of Musicology, Scientific Research Centre of the Slovenian Academy of Sciences and Arts, Ljubljana

\title{
"Sequamini o socii“ ali vesela glasbena druščina s Kranjske in Štajerske: Prva knjiga pet- in šestglasnih madrigalov Filippa de Duca (1586)*
}

\section{"Sequamini o socii" or the Merry Musical Company from Carniola and Styria: \\ The First Book of Five-and Six-Part Madrigals by Filippo de Duc (1586)}

Ključne besede: Filippo de Duc, madrigali, posvetila, družina Khisl, plemiški študentje v Padovi, Lenart Merherič, pivska pesem v latinščini in nemščini

\section{IZVLEČEK}

Posvetilo zbirke madrigalov Filippa de Duca iz leta 1586 omenja vrsto imen kranjskih in štajerskih plemičev. Zbirka je naslovljena na Janeza Jakoba in Karla Khisl, v nadaljevanju pa so omenjeni tudi oče Janez, brata Jurij in Vid ter "častitljiva druščinau: Friedrik in Jurij Hartman Stubenberg, Volk Egk in Hungerspach, Gašper Gleispach (vsi študentje prava v Padovi) ter njihov preceptor Hijeronim Megiser. En madrigal je posvečen Lenartu Merheriču. Prvi madrigal ima posvetilno besedilo, ki opeva oba osrednja posvečenca, in en drug verjetno hvali njuno sestro Ano Khisl. V zbirki je objavljen tudi primer pivske pesmi v mešanici latinščine in nemščine, ki živo ponazarja veselo življenje takratnih univerzitetnih študentov.
Keywords: Filippo de Duc, madrigals, dedications, Khisl family, noble students in Padua, Leonard Mercheritsch, drinking song in Latin and German

\section{ABSTRACT}

The dedication of Filippo de Duc's madrigal collection of 1586 contains a number of names of Carniolan and Styrian nobles. The collection is dedicated to Giovanni Giacomo and Carlo Khisl, but De Duc's dedicatory text praises also their father Hans and two brothers, Georg and Veit, as well as their "illustrious company" comprising Friedrich and Georg Hartman Stubenberg, Volcard Egk and Hungerspach, Kaspar Gleispach (all at the time students of law in Padua) and, finally, their tutor Hieronimus Megiser. The first piece has a dedicatory text that praises the two main dedicatees; one madrigal is dedicated to Leonard Mercheritsch, and a further one is possibly a compliment to Ana Khisl. The collection also contains a "goliardic" song in a mixture of Latin and German vividly illustrating the merry life of university students of the time.

\footnotetext{
" Prispevek je nastal kot moj osebni poklon profesorju Rijavcu, katerega duhovita in zanimiva predavanja so se nam - njegovim študentom dodobra vtisnila $\mathrm{v}$ spomin in nas nekatere, ob profesorjevih tiskanih delih, spodbudila k nadaljnjemu muzikološkemu delu. Profesor Rijavec je prvi v slovenski strokovni literaturi omenil De Ducovo zbirko madrigalov in prepričana sem, da bi se, če bi živel v daljnem 16 . stoletju, ki mu je namenil svoje doktorsko delo, tudi sam v študijskih letih z veseljem pridružil veseli glasbeni druščini, "compagnii«, o kateri pišem v svojem prispevku.
} 
"Blagorodnima gospodoma, gospodoma Janezu Jakobu in Karlu Khisl s Fužin in Konjic, itd., dednima lovskima mojstroma vojvodine Kranjske in Slovenske marke ter točajema preslavne Goriške grofije, svojima prečastitima pokroviteljema.

Novi knjigi pripada, skoraj tako kot to pristoji novemu svetišču, da je kot svetišče, čeprav je le-ta samo izdelek najbolj domiselnega stavbarstva, okrašen z najdražjimi kamni, torej z vsem tistim, kar, če ni posvečeno božjemu ali nebeškemu Duhu, ne bo nikoli posvečala in častila tako velika množica ljudi. Iz tega razloga sem si zaželel, da bi ta moja glasbena dela imeli pred očmi in jih častili bistri in virtuozni duhovi ter mi je prišlo na misel, da bi jih objavil pod okriljem Vajinih blagorodnih in slavnih imen, a tudi zato, ker sta že izven sveta amaterjev in sta podpornika vrlin, predvsem pa glasbe, tako kot tudi Vajin gospod oče, velezaslužni vitez in svétnik njegovega cesarskega veličanstva ter predsednik dvorne komore presvitlega nadvojvode Karla, in še Vajinih gospostev brata, to sta blagorodna gospod Jurij in gospod Vid. In to sem spoznal tudi ob stalnem muziciranju tako z Vašimi gospostvi kot tudi skupaj z vso Vašo častitljivo druščino, to je blagorodnima gospodoma bratoma Friderikom in Jurijem Hartmanom, baronoma Stubenberg, pa gospodom Volkardom baronom Egk in Hungerspach ter gospodom Gašperjem pl. Gleispachom, vsemi mojimi prečastitimi gospodi, skupaj z Vašim najzvestejšim učiteljem, gospodom Hijeronimom Megiserjem, ki naj Vam vsem Bog nakloni dobro in se Vam najponižneje globoko priklanjam." ${ }^{1}$

S temi besedami je v Padovi, 15. januarja leta 1586 (če je bila datirana po beneškem štetju, bi to seveda pomenilo, da je šlo pravzaprav za januar 1587$),{ }^{2}$ pospremil svojo prvo zbirko petin šestglasnih madrigalov, Il primo libro de madrigali a cinque et sei voci, nizozemski skladatelj Philippe oz. Filippo de Duc, in jo nato oddal v beneško tiskarsko delavnico družabnikov Giovannija Vincentija in Ricciarda Amadina. ${ }^{3}$ Glasbena zbirka, posvečena članom znane glasbene družine s Kranjskega, v slovenski muzikološki literaturi seveda ni ostala neopažena, beležke o njej pa so se vse do sedaj omejevale zgolj na osnovno posvetilo bratoma Janezu Jakobu in Karlu Khislu ter na splošno znana zgodovinska dejstva, ne pa tudi na glasbeni del zbirke in vsebino zgoraj navedenega posvetilnega besedila. ${ }^{4}$

O nizozemskem oz. flamskem (sam se imenuje "Fiamengo") skladatelju Filippu de Ducu je znanih le malo dejstev. ${ }^{5}$ Roditi se je moral nekje okoli sredine stoletja na Flamskem, prvi znani dokumenti o njegovi glasbeni poti pa so beležke o izplačilih dvorne kapele cesarja Maksimilijana II. na Dunaju, v kateri so pod vodstvom takratnega kapelnika prav tako Nizozemca Jacobusa Vaeta (umrl je januarja 1567) mladega De Duca glasbeno vzgajali in je pel v tamkajšnjem deškem zboru. ${ }^{6}$ Maja leta 1568 je bil iz cesarske blagajne izplačan denar ob zaključku njegove "službe"

\footnotetext{
Glej tudi transkripcijo posvetilnega besedila v Prilogi 1 oz. faksimilno reprodukcijo (slika 3).

Pri datumih beneških dokumentov je treba upoštevati tudi možnost datiranja po takratnem uradnem štetju (mos venetus), po katerem se je leto začelo 1. marca, in je zato treba dokumente iz januarja in februarja v našem štetju nominalno prestaviti v naslednje leto. Če je tiskar upošteval uradni koledar, bi bilo mogoče leto izdaje razumeti tudi kot januar 1587.

3 Izvirna naslovnica se glasi: "DI FILIPPO DE DUC FIAMENGO IL PRIMO LIBRO DE MADRIGALI A CINQUE ET Sei Voci, Novamente composti, et dati in luce. IN VENETIA Presso Giacomo Vincenzi, et Ricciardo Amadino, compagni. M DM LXXXVI." (RISM, Serija A/I: D 3613). Glej tudi faksimilno reprodukcijo (slika 1). Zbirka je popisana tudi v najpopolnejšem repertoarju italijanskih madrigalov: Emil Vogel [...], Bibliografia della musica italiana vocale profana pubblicata dal 1500 al 1700, zv. 1, Pomezia: Staderini-Minkoff, 1977, str. 573-574.

4 Prvi je na De Ducovo zbirko opozoril prav slavljenec pričujočega slavnostnega zbornika razprav. Gl. Andrej Rijavec, Glasbeno delo na Slovenskem v obdobju protestantizma, Ljubljana: Slovenska matica v Ljubljani, 1967, str. 116-117. Zbirko so pozneje omenjali tudi Janez Höfler, O nekaterih slovenskih skladateljih 16. stoletja, Kronika 23 (1975), str. 87-94: 92; Janez Höfler, Glasbena umetnost pozne renesanse in baroka na Slovenskem, Ljubljana: Partizanska knjiga, 1978, str. 30; predvsem pa Danilo Pokorn, Baroni Khisli in njihovo mecenstvo, Grafenauerjev zbornik, ur. V. Rajšp [...], Ljubljana: Znanstvenoraziskovalni center SAZU [...], 1996, str. 447-459: 456.

Osnovni biografski podatki so povzeti po večjih glasbenih leksikonih: Patricia Ann Myers, Duc, Filippo, The New Grove Dictionary of Music and Musicians, zv. 7, London [...]: Macmillan Ltd., 2001, str. 636-637 in Elizabeth Theodor Hilscher, De Duc, Philippe, Österreichische Musiklexikon, zv. 1, Wien: Österreichische Akademie der Wissenschaften, 2002, str. 305.

6 Več o članih, delovanju in pravilih dvorne kapele, odgovornosti kapelnika in njegovih pomočnikov za vzgojo dečkov ter navodilih za njihovo prehrano, oblačila, glasbeno delovanje izven kapele itd. v Walter Pass, Musik und Musiker am Hof Maximilians II, Tutzing: Hans Schneider, 1980 (= Veröffentlichungen zur Musikwissenschaft 20). Nekaj tudi v Carmelo Peter Comberiati, Late Renaissance Music at the Habsburg Court: Polyphonic Settings of the Mass Ordinary at the Court of Rudolf II (1576-1612), New York [...]: Gordon and Breach Science Publishers, 1987, str. 25-29.
} 
oz. usposabljanja. ${ }^{7}$ Verjetno je kmalu zatem odpotoval v Padovo, kjer je očitno deloval vsaj do leta 1586, ko se v dokumentih - prav v tisku, ki je predmet te razprave - zadnjič omenja. V to severnoitalijansko mesto je prišel najpozneje leta 1570, ko je v Benetkah 15. julija podpisal posvetilo svoje prve znane tiskane zbirke, Il primo libro de madrigali [... $]^{8}$

Njegova prva znana glasbena dela9 so bila objavljena leta $1568 \mathrm{v}$ antologiji Novus atque catholicus thesaurus musicus, ${ }^{10} \mathrm{ki}$ jo je pripravil in objavil Pietro Giovanelli (Petrus Joanellus) in jo posvetil cesarju Maksimilijanu II. oz. vladajoči habsburški cesarski družini. De Duc je prispeval kar deset svojih motetov, za katere je bil iz dvorne blagajne 30. septembra 1567, tako kot tudi njegov kolega Lambert de Sayve, nagrajen z dvajsetimi zlatniki. ${ }^{11}$ Svojih stikov z dvorom na Dunaju tudi po odhodu v Italijo ni povsem zanemaril, saj so mu leta 1577 iz dvorne blagajne izplačali še 25 zlatnikov za "dve maši “, ki ju je posvetil cesarju Rudolfu II. ${ }^{12}$ Ena od teh je verjetno v rokopisu ohranjena petglasna parodna maša na Palestrinov motet Io sono ferito. ${ }^{13}$

De Ducova duhovna dela, ki se jih je nekaj ohranilo tudi v rokopisih in dveh večjih tiskanih antologijah, ${ }^{14}$ so pisana v takrat sodobnem poznorenesančnem polifonem slogu, medtem ko vsa znana posvetna dela izpričujejo nagnjenost h lahkotnejšemu, psevdo-dramatičnemu glasbenemu jeziku, kot je izpričan za hibridne oblike tedanje madrigalne literature. ${ }^{15}$

Že v prvi knjigi štiriglasnih madrigalov, Il primo libro de madrigali a quattro voci, con una Serenata et un Dialogo a otto nel fine, je devetim slogovno raznolikim madrigalom z ljubezensko vsebino dodal še serenato, to je predhodnico krajše kantate v smislu štiridelnega dramatskega madrigala, in osemglasni dialog, ki prav tako sodi med zgodnje glasbeno-dramatske zvrsti. ${ }^{16}$ Zbirko, ki jo je natisnil eden od obeh najpomembnejših beneških glasbenih tiskarjev, Girolamo Scotto, je skladatelj posvetil vsem flamskim študentom v Padovi, ki jih v posvetilu nadvse hvali. ${ }^{17}$ Že v tej zbirki je De Duc pokazal, da je mojster sodobnega madrigalističnega pisanja, saj v madrigalih združuje "resne" principe tradicionalne polifonije s priljubljenimi lahkotnejšimi akordskimi, tudi kitičnimi zvrstmi, kot so bile vilanele, kanconete ipd. Vsebinsko parodira sentimentalno pripoved, ki ji prida občasno celo vulgarne tone. Za poudarjanje glasbenega izraza uporablja vrsto postopkov, ki so jih pozneje poimenovali s skupnim izrazom "madrigalizmi«. Leta 1774 je v Benetkah, tokrat

7 Podatek, ki ga avtorica gesla v The New Grove Dictionary of Music and Musicians ne pozna, prinaša geslo E. Theodor Hilscher, nav. delo, str. 305.

8 Di Filippo Duc il primo libro de madrigali a quattro voci, con una Serenata et un Dialogo a otto nel fine. Novamente posti in luce. In Vinegia, appresso Girolamo Scotto 1570. Navedeno po E. Vogel [...], nav. delo, str. 573.

9 O De Ducovih (posvetnih) glasbenih delih je doslej najpodrobneje pisal Alfred Einstein v svoji monumentalni knjigi o italijanskem madrigalu. Alfred Einstein, The Italian Madrigal, Princeton in New Jersey: Princeton University Press, 1949, str. 757-760.

10 Antologija, ki jo je natisnil beneški tiskar Antonio Gardano, obsega pet delov v petih glasovnih zvezkih: motete za vse glavne praznike liturgičnega leta, za vse nedelje, za vse svetniške praznike, motete v čast Mariji, apostolov, mučencev itd., ter posvetilne motete članom vladajoče družine. Izvod tega dela hrani tudi Glasbena zbirka Narodne in univerzitetne knjižnice v Ljubljani, Inv. št. 23784. Ljubljanski izvod je vezan v rjavo usnje v petih knjigah. Deloma je poškodovan, saj manjkajo naslovne strani in posvetila, ima pa na notranjih straneh platnic veliko rokopisnih zaznamkov, med katerimi je ime verjetno prvega lastnika (Adamus Sobalitsek), podpisana pa sta tudi dva ljubljanska škofa (Janez Tavčar in Tomaž Hren), saj so knjige iz protestantskih rok proti koncu stoletja ali pozneje očitno prešle v fond gornjegrajske knjižnice. Zanimivo je, da je bil za vezavo platnic notranje strani glasu sextus prvotno uporabljen testament Primoža Trubarja, ki je bil leta 1955 iz knjige strokovno izločen. Podroben opis dela in vsebine je objavljen v Mary S. Lewis, Antonio Gardano. Venetian Music Printer: 1538-1569. A Descriptive Bibliography and Historical Study, zv. 3, New York in London: Ruthledge, 2005, str. 355-388. O antologiji glej tudi Walter Pass, Reformation und katholische Erneuerung, Musikgeschichte Österreichs: Von den anfängen zum Barock, zv. 1, ur. R. Flotzinger, Wien [...]: Böhlau Verlag, 1995, str. 215-252: 229-230.

11 C. P. Comberiati, nav. delo, str. 99; in W. Pass, nav. delo, 1980, str. 150.

12 Albert Smijers, Die kaiserliche Hofmusik-Kapelle von 1543-1619 [III. Teil], Studien zur Musikwissenschaft 7 (1920), str. 102-142: 132.

13 Österreichische Nationalbibliotherk, Musiksammlung, Mus.Hs.15946, 38v-65. O parodnih mašah na Rudolfovem dvoru glej tudi C. P. Comberiati, nav. delo, str. 132-145, 154-155 (De Ducova maša z incipiti) in 177-181 (opis korne knjige z De Ducovo mašo).

$14 \mathrm{~V}$ že omenjenem Novus thesaurus musicus (1568) z desetimi De Ducovimi skladbami in v Tertius Gemae musicalis liber: selectissimas diversorum autorum cantiones. Italis madrigali et napolitane dictas, octo, septem, sex, quinque et quatuor vocum continens (Nürnberg: $\mathrm{K}$. Gerlach, 1590) z dvema skladbama Philippa de Duca. RISM Recueils imprimés XVIT-XVIT siècles: $1568^{2}, 1568^{3}, 1568^{4}, 1568^{5}$ in $1590^{20}$.

15 Anthony Newcombe, Madrigal: Italy: The 1570s: Hybrid Styles; The 1580s: The Ornamented Style; Dissemination of the Hybrid Style, The New Grove Dictionary of Music and Musicians, zv. 15, London [...]: Macmillan Ltd., 2001, str. 553-555; Jerome Roche, The Madrigal, Oxford in New York: Oxford University Press, 1990.

${ }_{16}$ Seznam skladb je objavljen v E. Vogel [...], nav. delo, str. 573. Analizo serenate prinaša A. Einstein, nav. delo, str. 758-760.

17 Transkripcija celotnega posvetila in opis zbirke je objavljen v: Jane A. Bernstein, Music Printing in Renaissance Venice: The Scotto Press (1539-1672), New York in Oxford: Oxford University Press, 1998, str. 449-451. Posvetilo je izrazito osebno in toplo ter seva skladateljevo domotožje po rodni Flamski. 
pri tiskarju Antoniu Gardanu, izšla njegova druga samostojna tiskana zbirka. ${ }^{18}$ Tokrat je zbirko motetov, Le Vergini, posvečeno paraduhovni temi "devic", ${ }^{19}$ naslovil na brata Giovannija in Giorgia grofa Montfort, ${ }^{20} \mathrm{ki}$ sta bila v tistem času najverjetneje študenta padovanske univerze. ${ }^{21}$ Morda se je pri tem delu zgledoval po istoimenski šest let zgodnejši zbirki padovanskega skladatelja Francesca Portinara, katere prva skladba, sedemglasni dialog, je posvečen cesarju Maksimiljanu II. ${ }^{22}$

Vsa znana De Ducova posvetna dela sodijo v skupino madrigalov, ki jo Alfred Einstein obravnava v okviru družabne glasbe za zabavo. Njegove zbirke navaja kot značilne primere glasbenega repertoarja, ki je živel med študenti večjih univerz izven takratnih "akademskih" krogov. ${ }^{23}$ Prav skladateljeva zbirka, posvečena leta 1586 veseli glasbeni druščini bratov Khisl, po njegovem mnenju predstavlja prerez skozi tedanji študentski glasbeni repertoar.

Univerza v Padovi, ustanovljena že leta 1222, je poleg študija prava (Universitas Iuristarum) nudila tudi "umetniški" študijski program (Universitas Artistarum), v okviru katerega so predavali astronomijo, dialektiko, filozofijo, gramatiko, medicino in retoriko, v okviru svobodnih umetnosti pa so poučevali tudi glasbo. ${ }^{24}$ Študentje so se delili na Italijane in "druge». Med zadnijmi je bila med 15. in 17. stoletjem še posebno močna skupina študentov "nemške narodnosti", med katerimi je bilo med drugim tudi veliko uka in še bolj plemenite zabave željnih Kranjcev in Štajercev. ${ }^{25}$ Prav v 16. stoletju je padovanska univerza doživela izjemen vzpon s svetovnimi dognanji na področjih medicine, astronomije in fizike. Zaradi sorazmerno velikih svoboščin, ki jih je omogočala beneška jurisdikcija, je univerzo obiskovalo tudi lepo število protestantskih plemiških sinov, kot so bili tudi vsi, ki jih De Duc imenuje v svojem posvetilu iz leta 1586.

Živahno kulturno dogajanje v Padovi je seveda vključevalo tudi glasbo, ki se je v mestu razcvetela ne samo v okviru cerkvenih glasbenih kapel, npr. stolnice in minoritskega središča, imenovanega Il Santo, temveč tudi pod okriljem mestnih humanističnih akademij (med 1556 in koncem stoletja je za krajši ali daljši čas delovalo vsaj šest večjih akademij, katerih pomemben del aktivnosti je prestavljala prav glasba) in celo bolj ali manj zasebnih glasbenih šol, ${ }^{26}$ društev in amaterskih krožkov. ${ }^{27}$ Glasbeniki, predvsem inštrumentalisti so bili tako iskani, da so se z glasbo lahko tudi preživljali in so občasno imeli celo svoja združenja, ${ }^{28}$ kar je morda veljalo tudi za Filippa de Duca.

Mesto je bilo tudi v sedemdesetih in osemdesetih letih, ki nas v zvezi z obravnavano De Ducovo zbirko še posebno zanimajo, zbirališče vrste bolj ali manj znanih glasbenikov in skladateljev.

18 Naklada je bila verjetno majhna, saj v prodajnem katalogu, ki so ga izdali tiskarjevi dediči leta 1591, zbirka ni več zabeležena. Prim. M. S. Lewis, nav. delo, zv. 3, str. 449-451.

19 Večina besedil je iz zbirke Antonia Paganija, Le rime spirituali, ki je izšla v Benetkah 1570, nekaj pa po tedaj povsem novi izdaji Gabriella Fiamme, Rime spirituali, prav tako tiskane v Benetkah leta 1573. Glej RePIM, ur. A. Pompilio: http://repim.muspe.unibo.it. O RePIM glej tudi op. 36, spodaj.

20 Monforti so bili pomembna avstrijska plemiška družina, ki je imela veliko posestev tudi na Štajersekm, v okolici Gradca. Sredi 16. stoletja je veljala celo za edino družino grofovskega stanu na Štajerskem. Glej Arnold Luschin-Ebengreuth, Studien zur Geschichte des Steierischen Adels im 16. Jahrhunderte, Mittheilungen des historischen Vereins für Steiermark 23 (1875), str. 6, op. 4 in str. 7, op. 5. Brata Georg in Hans grofa Montfort sta v osemdesetih letih 16. stoletja zabeležena kot lastnika gradu in mesta Peggau v bližini Gradca. Podatek je priobčen po Tobert Baravalle, Burgen und Schlösser des Steiermark, Graz: Stiasny Verlag, 1961, str. 167.

21 E. Vogel [...], nav. delo, str. 574-575.

22 Francesco Portinaro (ok. 1520-po 1577) je deloval predvsem v Padovi, kjer je leta 1555 ustanovil nekakšno kratkotrajno društvo glasbenikov (societas musicorum). Povezan je bi tudi z nekaterimi humanističnimi akademijami v mestu. Leta 1568 se je verjetno potegoval za prosto mesto kapelnika na Dunaju in je zato svojo zbirko Le Vergini, deloma na set Petrarkovih besedil v čast Devici Mariji, posvetil cesarju. Tudi sam je odšel v avstrijsko prestolnico, a se je leta 1569 vrnil v Padovo. Prav nekako v tem času se je z Dunaja v Padovo preselil tudi Philippe de Duc in se preimenoval v Filippo de Duc. Leta 1571 je Portinaro postal kapelnik v padovanski katedrali. O Portinaru glej Maria Archetto, Portinaro, Francesco, The New Grove Dictionary of Music and Musicians, zv. 20, London [...]: Macmillan Ltd., 2001, str. 189 in A. Einstein, nav. delo, str. 471-757.

23 A. Einstein, nav. delo, str. 757.

24 O zgodovini Padove glej spletno stran: http://www.unipd.it/ateneo/storia/storia.htm.

25 Glej tudi študijo Ingrid Matschinegg, Österreicher als Universitätsbesucher in Italien (1500-1630). Regionale und soziale Herkunft-Karrieren-Prosopographie, Graz: Karl-Franzens Universität Graz (doktorska disertacija), 1999, str. 27-31 (o univerzi v Padovi).

26 Znana je bila predvsem šola lutnjista Antonia Rote, ki je med drugim poučeval tudi vrsto "nemških" učencev. O Roti glej Elda Martellozzo Forin, Il maestro di liuto Antonio Rota $(\dagger 1549)$ e studenti dell'Università di Padova suoi allievi, Atti e memorie dell'Accademia patavina di scienze, lettere ed arti. Memorie della Classe di scienze morali, lettere ed arti 79 (1966-67), str. 425-443.

27 Prim. Pierluigi Petrobelli/Sergio Durante, Padua, The New Grove Dictionary of Music and Musicians, zv. 18, London [...]: Macmillan Ltd., 2001, str. 878-881: 879.

28 Glej tudi op. 22, zgoraj. 
Naj na tem mestu omenim le nekatere, navedene kot padovanske avtorje ("diversi nobili spiriti di Padova") v zbirki triglasnih kanconet, ki jih je zbral Angelo Barbato (znan v Padovi med 1583-1587 kot amaterski glasbeni založnik in skladatelj; sam je prispeval dve skladbi) in jih junija leta 1587 na pobudo Giovannija Battista Mosta (učenec Claudia Merula v Benetkah in v letih 1580-1589 kapelnik padovanske stolne cerkve; tudi avtor dveh kanconet) posvetil Vidu, Janezu Jakobu in Karlu Khisl, ${ }^{29}$ torej istim pokroviteljem, kot jim je dobro leto prej svoje skladbe poklonil Filippo de Duc: Annibale Padovano, Giulio Renaldi, Francesco Pigna, Marc'Antonio Pordenon, Domenico Paci, Giovanni Maria Renaldi, Luigi dalla Balla, Girolamo Boni, Francesco del Sole, Fede Saloni, Nadalino Dinarelli, Pier Andrea Bonini in Paulo Bozi. ${ }^{30}$
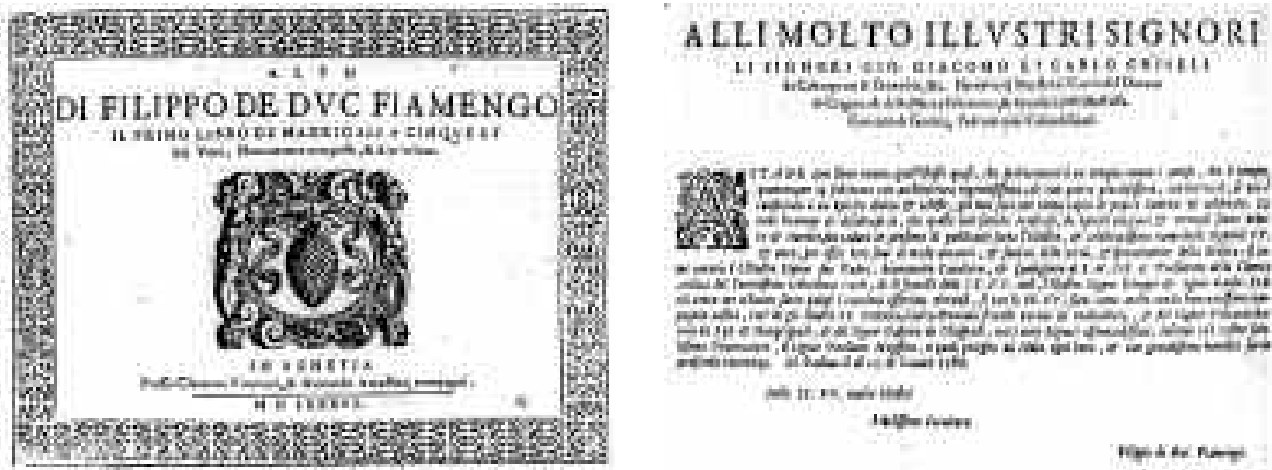

Sliki 1 in 2: Izvirna naslovnica in posvetilo v glasu alto. (Po izvirniku iz Bayerische Staatsbibliothek v Münchnu: sig. 4 Mus.pr. 189, Beibd. 3, z dovoljenjem.)

Edini znani izvirni natis De Ducove Prve knjige pet- in šestglasnih madrigalov se danes nahaja v Bavarski državni knjižnici (Bayerische Staatsbibliothek) v Münchnu (4 Mus.pr. 189, Beibd. 3). Pet glasovnih zvezkov je zvezanih v obsežnejše knjige, skupaj s še devetnajstimi drugimi glasbenimi deli, natisnjenimi z eno samo izjemo v Benetkah med 1563 in 1686. De Ducova zbirka, četrta po vrstnem redu, je najmlajša med zbranimi. Vse zbirke vsebujejo lahkotnejši tip posvetne italijanske vokalne glasbe; največ je petglasnih madrigalov, nekaj je tudi štiri- in šestglasnih madrigalov, ena zbirka prinaša neapeljske kanconete in nekaj maskerat, v zbirkah Mattea Flecche in Andree Gabrielija pa sta objavljena tudi osemglasna dialoga. Vsebinsko torej De Ducova zbirka ne odstopa od ostalih. Skupaj zvezanih dvajset glasbenih knjig je bilo prvotno del glasbene knjižnice Johanna Georga pl. Werdensteina (1542-1608), ki je bil znan zbiralec glasbenih del. ${ }^{31}$

29 Izvirna naslovnica se glasi: "CANZONETTE A TRE VOCI DI DIVERSI ECCELENTISSIMI MUSICI. LIBRO PRIMO. Novamente poste in luce. IN VENETIA, MDLXXXVII. Appresso Ricciardo Amadino," Posvetilo pa se glasi: "ALLI MOLTO ILLUSTRI SIGNORI LI SS. GUIDO GIO. GIACOMO ET CARLO CHISELI da Coltenprun, et Gonobiz, et Hereditarii Maestri di Caccia nel Ducato del Cragno, et della Marca Schiavona, et Scudieri dell'Illustriss. Contado di Goritia, Padroni miei Colendissimi. Non potevano queste Canzonette à Tre Voci composti da diversi nobili spiriti di Padova ricever maggior ornamento di quello, che puote loro porgere lo splendore di voi tre Illustrissimi Signori fratelli, ne cui giovenil petti, si come rende la stretta congiuntione del sangue con puro affetto, et volere una concordante armonia, cosi unite si porgono tutte quelle celesti doti, onde cotanto i più maturi, et perfetti ingegni vi pregiano, et ammirano; A voi dunque liete elle compariscono, poiche portando in fronte il glorioso nome vostro sicurissime sono dover esser al mondo via più care, et gradite. piacciavi di accettar la loro protettione con quell'affetto, co'l quale suole il Signor Gio. Battista Mosto ottimo conosciatore della benignita loro andar bene spesso predicando la cortesia, et il valore, ch'in voi unitamente riverisce, et ammira, et io baciandole humilmente la mano, prego a tutti tre l'adempimento d'ogni honorato vostro desiderio."

30 Podatki so zbrani iz kopije izvirnika (edini ohranjeni izvod se danes nahaja v poljskem Gdañsku), ki jo hrani Fondazione Cini v Benetkah. Zbirka je izšla pri Ricciardu Amadinu v Benetkah, prvič s posvetilnim pismom, drugič in tretjič pa brez (1589 in 1594). O zbirki in skladateljih iz Padove več v Paola Del Piero, Antologie polifoniche padovane nel XVI secolo, Rassegna veneta di studi musicali 2-3 (1986-87), str. 65-80.

31 Za podatke se zahvaljujem vodji glasbenega oddelka Bavarske državne knjižnice Sabine Kurth. Več o Werdensteinu glej v Richard Charteris, Johann Georg von Werdenstein (1542-1608): A Major Collector of Early Music Prints, Sterling Heights, Mich., Harmonie Park Press, 2006 (= Detroit Studies in Music Bibliography 87). 
De Ducova zbirka je bila natisnjena v beneški tiskarski delavnici Giacoma Vincentija in Ricciarda Amadina, prav tako kot tudi Canzonette a quattro voci [...] libro primo Matthie Ferrabosca, sicer člana graške glasbene kapele, ki jih je avtor posvetil očetu že omenjenih bratov Khisl, Janezu, leta 1585 oz. 1586, če je bil tisk izdan po uradnem beneškem štetju. ${ }^{32}$ Tiskarja sta imela skupno tiskarsko delavnico prav v letih 1583 do 1586, potem pa sta se prijateljsko ločila in tiskala vsak samostojno, Vincenti tudi še globoko v 17. stoletju. Natisnila sta približno 20 knjig letno, kar pomeni, da je iz skupnega podjetja izšlo okoli 80 predvsem glasbenih knjig, med katerimi so bili tudi prvotiski takrat najbolj znanih skladateljev, kot so na primer Asola, Bassano, Marenzio, Stivori itd. ${ }^{33}$ Izdaja De Ducovih mardigalov je značilno prečnega formata z borovim storžem v tiskarskem znaku ${ }^{34}$ (glej tudi sliko 1) in je le skopo ornamentirana; celo inicialke so le rahlo okrašene (glej tudi sliko 3). Nekaj je tiskarskih napak, na primer pri označevanju glasov, sicer pa je glasbeno tisk precej zanesljiv. Notni zapis je jasen in opremljen z akcidencami, celo na mestih, kjer jih za rabo poklicnih glasbenikov ne bi bilo potrebno tiskati. Einstein je sklepal, da je bil tisk namenoma jasen in preprost, saj naj bi naročnik ne bil tako vešč glasbenik. ${ }^{35}$

\section{VSEBINA ZBIRKE}

- Giovan Giacomo et Carlo

- Quanto di bel il cielo

- Alma leggiadra e bella Partomi vita mia (Seconda parte)

- Errando un dì per un bel prat'ameno

Et io chi bramo una di quell'al seno (Seconda pate)

\section{- Anna bella gentil cortes' et saggia}

Luce degl'occhi miei (Seconda parte)

- Lucente Apollo a salutar venia

All'hor vedendo il suo bel viso (Seconda parte)

Che nova luce hor m'arde (Terza parte)

- Deh hor foss'io co'l vago della luna

- Non è questa la mano

- Prima ch'il paradiso

- Non hai potuto in cotanti anni Amore Al sign. Leonardo Mercherich

Ma se d'honor ti cale (Seconda parte)

(A sei) Et tu che vincerai (Terza patre)

- La piaga ch'hò nel core

- Sequamini ò socii. Zu einem guten vulen wein

Sint bacho grates. Der uns den wein (Seconda parte)

- Sapete voi qual sia (Alla Napolitana)

32 Izvirna naslovnica se glasi: "CANZONETTE A QUATTRO VOCI DI MATTHIA FERRABOSCO DA BOLOGNA: Servitore del Sereniss. Arciduca Carlo d'Austria. LIBRO PRIMO. Novamente composte, et date in luce. IN VENETIA Presso Giacomo Vincenzi, et Ricciardo Amadino, compagni, MDLXXXV." Posvetilo pa se glasi "Al molto Illustre Signor Cavaglier Cesareo: Il Signor Giovanni Khisl da Khaltenprun Khisltein, et Gonoviz, Capitano di Postoima, Supremo Mastro di Caccia del Cragno, et della Marcha di Schiavonia, Gran Scudiero del Contado di Goritia, Consigliero di S. Mae. Cesarea, et Presidente della Camera Aulica del Sernissimo Principe Carlo Arciduca d'Austria, mio Sign. colendissimo." Glej Hellmut Federhofer, Matthia Ferrabosco, Musica disciplina 7 (1953), str. 205-233. Glede datacije prim. tudi op. 2, zgoraj.

33 Thomas W. Bridges, Vincenti [Vincenci, Vincenzi], Giacomo, The New Grove Dictionary of Music and Musicians, zv. 26, London [...]: Macmillan Ltd., 2001, str. 651-652; Thomas W. Bridges, Amadino, Ricciardo, The New Grove Dictionary of Music and Musicians, zv. 1, London [...]: Macmillan Ltd., 2001, str. 440-441.

34 Ta znak je po ločitvi obdržal Vincenti. De Ducova zbirka je bila v prodaji podjetja Vincenti vsaj še do leta 1696, ko je zabeležena kot št. 49 v njegovem prodajnem katalogu in je stala 12 soldov. Glej Oscar Mischiati, Indici, cataloghi e avvisi degli editori e librai musicali italiani dal 1591 al 1598, Firenze: Olschki, 1984.

35 A. Einstein, nav. delo, str. 757. 
Zbirka vsebuje trinajst madrigalov, od tega je deset petglasnih in trije šestglasni. Štiri skladbe so dvodelne in dve tridelne. Uglasbena besedila so glede kvalitete zelo raznolika od vrhunske poezije do anonimnih del v slogu popularnih popevk tipa vilota (it. villotta) ali vilanela (tudi napolitana), pa skladateljevega avtorskega dela, in celo presenetljive mešanice latinščine in nemščine v pravi študentski pivski pesmi v slogu mnogo zgodnejše vagantske lirike.

Predvsem s pomočjo sedaj javno dostopnega repertoarja italijanske posvetne vokalne glasbe, Repertorio della Poesia Italiana in Musica, 1500-1700, ${ }^{36} \mathrm{sem}$ lahko identificirala besedilne vire pètih madrigalov, ostala besedila pa ostajajo anonimna. Razen že omenjenega Filippa de Duca, ki je nedvomno sam sestavil besedilo svojega posvetilnega madrigala (prvi madrigal, ki opeva brata Jurija Jakoba in Karla Khisl, ki jima skladatelj posveča svoje pesmi), je zadnji madrigal "Alla Napolitana", Sapete voi qual sia, donna la pena mia, iz zbirke lahkotnih pesmi Antona Giacoma Corsa Le rime (1550), ${ }^{37}$ tridelni madrigal, ki ga je skladatelj uglasbil za Lenarta Merheriča (Leonardo Mercherich), Non hai potutto in cotanti anni Amore, je kvalitetna ljubezenska poezija iz zbirke rim toskanskih pesnikov, ki jih je leta $1565 \mathrm{v}$ Benetkah dal tiskati Pompeo Pace, ${ }^{38}$ Non è questa la mano, che tante e si mortali, osmi madrigal De Ducove zbirke, ${ }^{39}$ pa je uglasben na besedilo iz zbirke Rime Torquata Tassa, ki je bil v Padovi v šestdesetih in sedemdesetih letih 16. stoletja celo osebno znan in zato seveda še toliko bolj priljubljen pesnik. ${ }^{40}$ Prav besedilo tega madrigala je bilo v začetku osemdesetih let še posebno priljubljeno in je doživelo vrsto madrigalnih uglasbitev; med 1579 in 1586 je v tiskih izšlo kar deset uglasbitev, do konca stoletja pa še sedem in razen treh so bili vsi tiskani v Benetkah. Med bolj znanimi uglasbitelji tega besedila so Luca Marenzio (1581 in 1594), Ruggiero Giovanelli (1588 in dva ponatisa), Giovanni Giacomo Gastoldi (1588) ter Philippe de Monte (1591).

Najkvalitetnejše je nedvomno besedilo sedmega madrigala De Ducove zbirke, Deh, hor foss'io col vago della luna, izpod peresa Francesca Petrarke. Kot večina pesnikovih del iz njegove zbirke Il Canzionere, je bil tudi ta odlomek 237. pesmi tega dela,${ }^{41}$ deležen velike pozornosti skladateljev. Morda zaradi prefinjene ljubezenske vsebine, pa motiva neuslišanega hrepenenja in aluzije na samo "pesem": ${ }^{42}$

Dal Bog, da bil bi že z ljubimcem lune

zaziban v sen med bujnimi gozdovi;

ko ta, ki mi priganja mrak večera, prišla bi z njo in z Amorjem k obali in $\mathrm{z}$ mano sama bi ostala $\mathrm{v}$ noči, a sonce, dan, ne vzšla bi več iz vala!

Nad krutim valom, ob bleščavi lune, pesem, rojena $\mathrm{v}$ noči med gozdovi, obalo uzreš mi jutri do večera!

36 Podatkovna zbirka Repertorio della Poesia Italiana in Musica, 1500-1700 (=RePIM), ki jo ureja Angelo Pompilio, je dostopna na spletnih straneh Univerze v Bologni, Oddelek za glasbo in predstavitvene umetnosti (Università di Bologna, Dipartimento di Musica e Spettacolo) na že citirani strani http://repim.muspe.unibo.it.

37 Znana je samo uglasbitev Filippa de Duca.

38 Pompeo Pace, De le rime di diversi nobili poeti toscani raccolte da M. Gionigi Atanagi, libro secondo, Venetia: Lodovico Avanzo, 1565. Poleg De Ducove ni znana še kakšna druga uglasbitev te pesmi.

39 Znana je samo De Ducova uglasbitev tega besedila.

40 Tasso, ki se je po letu 1564 iz Bologne umaknil v bolj svobodomiselno Padovo, je v tem mestu ustanovil celo svojo akademijo, Accademia degli Eterei. A. Einstein, nav. delo, str. 472-473.

41 Skladatelj je uglasbil zadnjih devet stihov pesmi št. 237, Non à tanti animali il mar fra l'onde. Glej Francesco Petrarca, Il Canzionere, ur. Giuseppe Rigutini, Milano: Ulrico Hoepli, 1908, str. 291-294. Zbirka Il Canzionere vsebuje 366 pesmi za vsakodnevno branje v enem koledarskem letu. Večinoma so soneti, osrednja figura pa je Laura oz. "ona", stilizirana ženska, ki pooseblja idealno ljubezen, lepoto in vero, opeva pa jo tako še za časa življenja kot tudi potem, ko je bila že mrtva.

42 Spodaj navedeni prevod je delo Andreja Capudra v dvojezični izdaji Francesco Petrarca. Izbor in prevod po: Canzionere, prev. Andrej Capuder, Ljubljana: Založba Mladinska knjiga, 1998, str. 74-77. 
Prav zbirka Il Canzionere, čeprav jo je sam Petrarka imel za drugorazredno in jo temu primerno poimenoval Rerum vulgarium fragmenta, je v 16. stoletju doživela izjemno popularnost. Od Aldinovega beneškega natisa leta 1501 v redakciji Pietra Bemba je doživela vrsto ponatisov, tudi priročno "Žepno" izdajo, priljubljeno med mladimi plemiči dobrega okusa in izobrazbe. Verjetno so se med te prištevali tudi mladi Khisli, Stubenbergi in drugi iz druščine, ki ji je Filippo de Duc posvetil svojo zbirko madrigalov. Vsekakor je znano, da so bila Petrarkova dela poleg Dvorjana Baldassara Castiglioneja, obvezni izvodi v knjižnicah kranjskih plemičev, rojenih okoli sredine 16. stoletja. ${ }^{43}$ Petrarkova oz. petrarkistična melanholična ljubezenska besedila so bila kot nalašč za prosto glasbeno obliko (madrigal), ki se ni več oslanjala na vodilno sopransko linijo zgodnejših frotol. Iz 16. stoletja je znanih skupaj sedemnajst uglasbitev zgoraj navedenega Petrarkovega šesterca. Vse razen dveh so izšle v Benetkah tiskanih zbirkah madrigalov, predvsem štiriglasnih. ${ }^{44}$ Zanimivo je, da je zadnja znana uglasbitev pred De Ducovo izšla v zbirki madrigalov padovanskega skladatelja Marc'Antonia Pordenona, ki je znan tudi iz že omenjene zbirke kanconet Angela Barbata iz leta 1587..5

Dve besedili, ki sta sicer anonimni, sta bili že pred letom 1586, ko ju je uporabil De Duc, večkrat uglasbeni, Alma leggiadra e bella (tretji madrigal) in La piaga ch’hò nel core (enajsti madrigal). Sodita med lahkotnejši zvrsti blizu anonimnim kanconetam in vilanelam. Alma leggiadra e bella, sin dal'età novella je znana tudi iz druge knjige štiriglasnih vilanel Guglielma Gonzage iz leta 1585. Znanih je nadalje šest uglasbitev besedila La piaga [...] in razen dveh (De Duc in Orazio Vecchi) so vse dejansko uglasbene kot strofične kanconete. ${ }^{46}$ Pri obeh madrigalnih skladateljih pa je opazno za tisti čas značilno mešanje posvetnih zvrsti in stapljanja elementov visokega nizozemskega polifonega sloga s priljubljenim akordskim kitičnim slogom z refreni, kar je tudi sicer ena od značilnosti De Ducovega glasbenega sloga.

Glede mešanja različnih besedil in žanrov je zanimiv tudi madrigal Anna bella gentil, katerega drugi del Luce degl'occhi miei je začetek neapeljske vilanele z nadaljevanjem perché si cruda e dispietata sei (znana iz štiriglasne uglasbitve Giovannija Domenica Montelle iz leta 1574). V De Ducovi uglasbitvi "Seconda parte" razen začetka ne povzema besedila znane vilanele. Po analogiji s podobnimi pesmimi tistega časa, za katere so že dokazali, da se naslavljajo na prav določene osebe, gospe, ${ }^{47}$ bi lahko morda sklepali, da tudi besedilo prvega dela De Ducovega madrigala pravzaprav govori o prav določeni Ani, ki jo je skladatelj poznal. Morda bi lahko bila to celo Ana Khisl, ${ }^{48}$ sestra nosilcev glavnega posvetila in leta 1577 opevana prečudovita nevesta vdovca Adama Egk in Hungerspacha $\mathrm{z}$ gradu Brdo pri Kranju, ${ }^{49}$ strica Volkarda Egk in Hungerspacha, enega od poimensko omenjenih članov Khislove druščine iz leta 1586. Ana se

43 Maja Žvanut, Od viteza do gospoda, Ljubljana: Viharnik: Znanstveni inštitut Filozofske fakultete, 1994, str. 154, 161-162. Marko Mugerli v svoji študiji ugotavlja, da so v tistem času italijanske knjige predstavljale približno 3 odstotke del v knjižnicah kranjskega plemstva. Glej Marko Mugerli, Pomen in vloga izobrazbe v plemiškem stanu od 16. do 18. stoletja, Ljubljana: Filozofska fakulteta Univerze v Ljubljani (magistrska naloga), 2003, str. 47. Maja Žvanut, Knjižnice na Kranjskem v 16. stoletju, Zgodovinski časopis 41 (1987), str. 277-283.

44 Od leta 1560 pa do De Ducove so znane uglasbitve naslednjih avtorjev: Orlando di Lasso (1560), Ippolito Camaterò (1561), Cipriano de Rore (1562), Salvatore Essenga (1566), Giovanni Pierluigi Palestrina (1568), Giovanni Nasco (1569), Biagio Pesciolini (1571), Marc'Antonio Pordenon (1571). Glej spletno stran http://repim.muspe.unibo.it in prim. op. 36, zgoraj.

45 Prim. op. 30, zgoraj.

46 Glej spletno stran http://repim.muspe.unibo.it in op. 36, zgoraj. Ostali skladatelji, ki so posegli po istem besedilu, so: Antonio Mogavero (1591), Flaminio Tresti (1594) in dva neimenovana (1584 in 1589).

47 Robert Lindell, Marta gentile, che'l cor m'ha morto - Eine unbekannte Kammermusikerin am Hof Maximilians II, Musicologica austriaca 7 (1987), str. 59-69. Zanimivo je, da je bila Gorzanisova vilanela Marta gentile objavljena prav v zbirki, posvečeni Juriju Khislu.

48 O Ani Mariji Khisl glej Barbara Žabota, Rodbina Khisl - novoveška zgodba o uspehu, Kronika 51 (2003), str. 1-26: 15-16. Iz ene od obeh posvetilnih pesmi - daljše izpod peresa Thobiasa Stengla -, ki sta nastali za to poroko, izvemo, da je bila Ana lepa po telesu in duši, ter da je imela rdeča usta, blede roke in slonokoščen vrat, ki so ga krasile zlate ogrlice z jaspisi in smaragdi, črne oči, rdeče-zlate lase, spete v zlati mreži in naglavni trak posut z dragimi kamni, nosila pa je biserne uhane. Avtor jo primerja z mitološkimi ženskami, saj da je zvesta kot Penelopa, da pa je tudi sramežljiva in mila. Navedeno po B. Žabota, nav. delo (2003), str. 15. Glej tudi Carmen encomiasticum: in celebres nuptias generosi, et clariss: viri, domini Adami L. Baronis an Eck et Hungersbach, domini in Flednich, etc. sponsi [...] d.nae Annae Chisildis, Labacum: I. Manlii, 1577. Izvirnik hrani Rokopisna zbirka Narodne in univerzitetne knjižnice v Ljubljani.

49 Lidija Slana, Brdo pri Kranju, Ljubljana: Arterika, 1996, str. 51. Za vse podatke o družini Egk in Hungerspach in pomoč pri iskanju ustrezne literature o Volkardu se gospe Lidiji Slana na tem mestu najlepše zahvaljujem. 
je dve leti po soprogovi smrti (umrl je 1589) še enkrat poročila in to v Gradcu z nekim Janezom Gleispachom, ${ }^{50}$ ki je bil po vsej verjetnosti sorodnik Štajerca Gašperja Gleispacha (tudi Kaspar, Caspar ali Gasparo), od leta 1584 člana Khislove glasbene druščine v Padovi, sicer pa študenta prava in vojaka. ${ }^{51}$

Anna bella gentil cortes'et saggia d'ogni virtù di fede e d'amor tempio stella del alto ciel, ch'oue s'irraggia L'alta beltà ne pat'ogn'altro scempio.

Luce degl'occhi miei, lucido sole, riposo del mio cor alma mia bella, Deh per pietà non siate si rubella.

Ahi che mi fate torto, l'asciandomi mancar senza consorto.

Ker glede številnih znanstev z notranjeavstrijskim plemstvom ni izključeno, da je skladatelj De Duc družino svojih posvečencev v času njihovega znanstva ${ }^{52}$ obiskal tudi na domu, na primer na Fužinskem gradu pri Ljubljani, bi zelo verjetno tam lahko spoznal tudi Ano. Zdi se, da je bil v tem primeru nad njo celo navdušen in ga je očarala, vendar ostaja zadržan in njenega imena ne razkriva, kar se zdi, glede na to, da se je bila medtem poročila, seveda tudi logično. V primeru, da je moje sklepanje o posvetilni naravi besedila De Ducovega madrigala pravilno, bi to pomenilo, da zbirka vsebuje poleg številnih že omenjenih posvetil iz uvoda tudi dve glasbeni posvetili, eno glavnima posvečencema in drugo Ani, sestri le-teh.

Tako Anna gentil kot tudi uvodna posvetilna skladba Giovan Giacomo et Carlo sta uglasbena kot kvalitetna madrigala v priljubljenem "hibridnem" slogu sedemdesetih in osemdesetih let 16. stoletja. ${ }^{53}$ Oba madrigala sta petglasna in grajena $v$ zmerno imitativni polifoniji. Začetki verzov so imitativni, predvsem na začetku skladbe, medtem ko so notranje kadence med posameznimi verzi manj izrazite. Polifona zgradba zaradi pretežno jasne silabične obravnave besedil, torej poudarjene deklamativnosti, daje vtis večje preglednosti in razumljivosti, ki je bila sicer značilnost lahkotnejših posvetnih vokalnih zvrsti. Glasba ni virtuozna in madrigalizmi ter virtuoznejše pasaže so redke, očitno zato, ker so bile skladbe vendarle namenjene muziciranju amaterskih plemiških glasbenikov in ne poklicnim pevcem - virtuozom.

Tovrstni madrigali so bili v zadnjih desetletjih tako priljubljeni, da so se v njih skladanju preizkušali celo bolj nadarjeni amaterji, med katere je nedvomno sodil tudi naš Janez Jakob Khisl. Leta 1591 je namreč v Benetkah pri Ricciardu Amadiniju izdal lastno zbirko madrigalov in motetov za štiri in pet glasov Il primo libro de Madrigali et Motetti a 4 et 5 voci composti gia dal molto ill. Signor, il Signor Giovanni Giacomo Khisl L. Barone in Kaltenprun, Khiselstain et Gonobitz etc. [...]. Več kot naslov se do danes žal ni ohranilo, tako da o glasbeni vsebini zbirke ne moremo govoriti. ${ }^{54}$

Pri Anna gentil tako razen manjše predkadenčne okrasne melodične fraze na besedo "Saggia" v obeh najvišjih glasovih, pa v pasaži hitrih "črnih" not na "ogn'altro" v zaključnem verzu prve-

50 B. Žabota, nav. delo (2003), str. 16.

51 I. Matschinegg, nav. delo, str. 378. Gašper Gleispach je bil sin Wilhelma in brat Jorga Andreasa in Sigismunda. Na univerzo v Padovi se je med juriste vpisal 1. junija 1584 , leta 1585 pa ga septembra zasledimo na univerzi v Sieni in oktobra istega leta na univerzi v Bologni.

52 Med 1570, ko je v Padovi spoznal očeta Janeza, pa verjetno tudi Jurija Khisla in Wolfganga, poznejšega skrbnika obeh v posvetilu imenovanih baronov Stubenberg, in 1584-1586, ko je mlajša druščina tam študirala. Glej tudi op. 58 in 69, spodaj.

53 Glej A. Newcombe, nav, delo, str. 553-555 in J. Roche, nav. delo, str. 46-91.

54 Naslov je znan iz nekaterih starejših katalogov (Draudius) in virov kot je Gerberjev leksikon. Glej Othmar Wessely, Tubingensia, Die Musikforschung 7 (1954), str. 397-402: 400-401; J. Höfler, nav. delo (1975), str. 92 in 94. 
ga dela, ko v ponovitvi basso imitira melodično frazo, ki jo prvi prinaša tenore, niso opazni drugi elementi virtuoznega sloga. Morda lahko omenim še poskus glasbenega slikanja na besedo "alto ciel" (visoko nebo), kjer se melodija v glasu cantus povzpne do najvišje točke, minime $\mathrm{e}^{2}$. Oba dela se začenjata z zaporednim vstopanjem glasov, ki prinašajo enak ritmično-melodični motiv. V prvem delu vstopajo glasovi po naslednjem redu: alto - canto - tenore - basso - quinto (ta je zapisan v tenorskem ključu in predstavlja drugi tenor; verjetno zato, ker je bilo v družbi, ki jim je bila zbirka namenjena več moških glasov kot sopranov), v drugem pa: canto - alto in quinto (v vzporednih tercah) - tenore - basso. Skladba ostaja v obeh delih v isti A-tonaliteti finalis na a brez predznakov za ključem in s tremi višaji v notnem zapisu, kar pomeni, da je bil De Duc na tekočem s tedaj še sorazmerno novim sistemom dvanajstih modusov.

Oglejmo si še glasbene značilnosti osrednje posvetilne skladbe De Ducove prve knjige petin šestglasnih madrigalov (skladba je v celoti transkribirana v Prilogi 2). V tem elegantnem madrigalu Filippo de Duc ni preveč eksperimentiral in se je očitno bolj zanašal na tradicionalno oblikovanje v smislu niza jasno ločenih glasbenih delov, sosledja polifonih in homofonih delov, ki pa ne sledijo vedno besedilnim odsekom. Besedilo je namreč deljeno na tri dovolj jasne dele po 3 , 4, in 3 verze. V prvem je opis naslovljencev, drugi hvali njune vrline in skromno govori o poklonjeni "pesmi“, tretji pa izraža iskreno prijateljstvo. Skladatelj vseskozi ohranja vzvišeno alla breve mero, glasbeno teksturo pa jasno deli v kontrapunktske polifone in akordske odseke.

Giovan Giacomo et Carlo, spirti felici et rari,

di generoso ardir di virtu pari.

Di vostri merti al segno, non gionge stil di pelegrino ingegno, ne'l mio si roco canto, può darvi pregio o vanto.

Pur consacro Chisel, al vostr'honore lo stil e'l canto, e'l canto e'l core.
Janez Jakob in Karel, srečna in izjemna duhova, obdarjena s plemenito drznostjo in vrlinami.

Do vajinih zaslug ne seže slog velike spretnosti, kajti moja pesem je hripava in prinašati vama ne more časti in bvale.

A kljub temu, Khisla, Vajini časti posvečam svoj slog in pesem ter pesem in svoje srce.

Kot pri drugih madrigalih te zbirke tudi tu posamezni glasovi imitativno vstopajo z značilnimi ritmično-melodičnimi signalnimi motivi. Besedilo je obravnavano pretežno silabično, brez daljših melizmov, razen na najočitnejše besede kot je na primer "canto" (pesem; m. 25-26, 36-37, pred- 
vsem pa v nekoliko bolj ornamentirani zaključni kadenci v m. 44). Sicer pa je glasbeni stavek preprost in jasen; le občasno nastopajo minimalne kadenčne okrasne note manjših vrednosti, kot na primer na ime "Carlo" $\mathrm{v}$ quinto in alto (m. 7 in 9). Tam, kjer je skladatelj želel, da se besedilo jasno razume, ga je uglasbil deklamativno akordsko, na primer v prvem odseku vzklik "spirti felici et rari“ (m. 7-8), kjer je poseben efekt dosegel tudi z izmenjavo samo treh zgornjih glasov s tutti. Hitri akordski parlando je uporabil za odsek besedila "non gionge stil di pelegrino ingegno" (m. 22-23) v drugem vsebinskem delu besedila. Glasbeno najjasnejša je cezura pred tretjim delom, kjer je teža posvetila: „Pur consacro Chisel», pri katerem vsebine ni poudaril le z akordsko obravnavo temveč tudi z dolžino not (m. 29-30 in 38-40).

De Ducov posvetilni madrigal pa ni bil prvi te vrste posvečen kakemu domačemu plemiču. Leta 1556 je prav tako flamski skladatelj, ki je deloval v Italiji, Cipriano de Rore, skupaj s pismom iz Ferrare poslal ostarelemu Wolfu Auerspergu s Šumberka svoj posvetilni latinski petglasni madrigal Rex Asiae et Ponti, ki je bil mnogo pozneje dvakrat natisnjen; prvič v zbirki Le Vive Fiamme de'vaghi e dilettevoli Madrigali dell'eccelentissimo Musico, Cipriano Rore [...] (Benetke, 1565) in drugič v De Cipriano de Rore il Quinto libro di Madrigali a cinque voci (Benetke, 1566). ${ }^{55}$

Med "resnimi" madrigali obravnavane zbirke, uglasbenimi na zgoraj opisan način, ne manjka tudi pastoralno-liričnih, melanholično-ljubezenskih in celo mitološko obarvanih tematik, ki so bile tudi sicer značilnost tedanje madrigalistične literature in uporabljenih literarnih virov. Med temi so seveda v prvi vrsti Deh hor foss'io co'l vago, na Petrarkovo besedilo, a tudi tridelni madrigal Non hai potuto in cotanti anni, na besedilo toskanskega avtorja. Prva dva dela madrigala sta petglasna, tretji, pa v smislu komentarja za zbor - šestglasen. Ta skladba ima poleg glasbene vrednosti tudi poseben pomen za kulturno zgodovino, saj je oseba, ki ji je delo posvečeno, Lenart Merherič, čeprav je bil dosedanjim muzikologom, ${ }^{56} \mathrm{ki}$ so posvetilo opazili, neznan, v slovenski zgodovini, kot bomo videli v nadaljevanju, dovolj opaženo ime. Je pa zanimivo, da je v kontekstu De Ducove zbirke njegovo ime prvič povezano z glasbo, s skladbo izrazito ljubezenske vsebine.

Zagotovo med zanimivejše skladbe sodi tudi Luccente Apollo a salutar venia la delicata Aurora. Gre za nekakšno "serenado“, ki ob sklicevanju na mitološke vsebine pravzaprav opeva lepoto gospe z razpeto pletenico (po mnenju Einsteina je to personifikacija mesta Padove), pred katere lepoto v prvi zori bleščeči Apolon skrije svoj obraz. Od treh delov je prvi opis zore in lepote "gospe", v drugem, All'hor vedendo il suo bel viso, se Sonce, ob pogledu na njeno lepoto obrne na Apola, ki mu v tretjem delu, Che nova luce hor m'arde, oznani, da sedaj sveti nova luč in Apolon je osramočen.

Zadnja skladba zbirke Sapete voi qual sia je označena "Alla Napolitana", vendar njen neapeljski značaj ne razkrivata niti formalna (ni namreč skladana kot vilanela, čeprav bi besedilo lahko predstavljalo kitico le-te) niti jezikovna plat, bolj lahkotna vsebina samega besedila in skriti refren. Gre torej za madrigal, v katerem je prisoten namig na lahkotnejšo glasbeno obliko v smislu hitre deklamacije in kvazi-dramatske izmenjave različnih skupin glasov z "zborom" oz. tutti deli za šest glasov. Na refren spominja tudi odsek besedila, ki se rahlo variiran trikrat ponovi "Onde di nuovo ve lo torn'à dire".

Še bolj kot lahkotnost zadnje skladbe pa na pestrost študentske glasbene poustvarjalnosti in to ne le v literarni italijanščini temveč tudi v drugih jezikih, s poudarkom na veselih, občasno celo vulgarnih tonih skupnega veseljačenja, spominja najbolj nenavadna skladba te zbirke - napitnica oz. kot jo imenuje Alfred Einstein "himna Bachusu" Sequamini o socii-Zu einem guten vullen Wein. Preseneča nas manj njena vsebina, saj je jasno, da so v svojem študentskem živ-

55 Bernhard Meier, Rex Asiae et Ponti. Poklonitveno delo Cypriana de Roreja, Muzikološki zbornik 6 (1970), str. 5-11. Glej tudi izdajo Bernhard Meier, Cipriani Rore, madrigalia 3-8vocum. Opera omnia, zv. 5, Rome: American Institute of Musicology, 1971 (= Corpus mensurabilis musicae 14), str. XI-XII in 88-91.

56 Alfred Einstein je na primer "po njegovem imenu" napačno sklepal, da je bil iz spodnjega Porenja. A. Einstein, nav. delo, str. 757. Več o Merheriču v op. 92 in 93 , spodaj. 
ljenju mladi plemiči, ki tudi niso bili povsem brez sredstev, veseljačili, kot dejstvo, da je skladatelj tovrstno skladbo dal tudi natisniti. Je imel za to kak poseben razlog? Je to sploh njegova skladba, ali jo je zaradi posebne priljubljenosti med v posvetilu omenjenimi člani kranjsko-štajerske druščine kot šalo vključil v zbirko? Glasbeni del morda celo govori v prid De Ducovemu avtorstvu, o družabnem življenju naše plemiške mladine pa še nekaj v nadaljevanju.

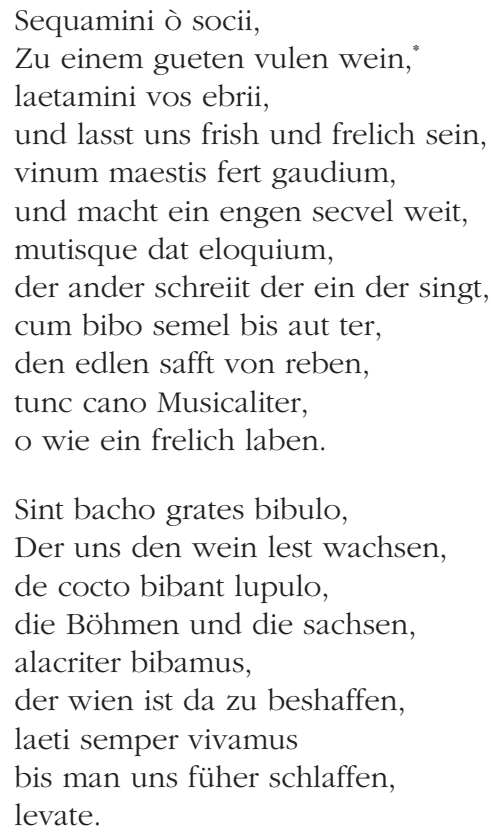

Skladba je šestglasna in ima dva formalna dela, besedilo pa je v slogu nekaterih pivskih Carmina Burana pol latinsko in pol nemško, ${ }^{57}$ kot kaže zgoraj navedeno celotno besedilo. Latinski del je ortografsko in slovnično pravilnejši kot nemški ("prepis namenoma točno sledi izvirniku), kar kaže na večjo neizdelanost nemškega pravopisa v 16. stoletju oz. slabše poznavanje tega jezika od latinščine. Kar se tiče uglasbitve je značilno to, da so latinski deli polifono bolj izdelani glasovi na primer kot $\mathrm{v}$ drugih madrigalih vstopajo imitativno z značilnim uvodnim ritmičnomelodičnim motivom kvintnega skoka in ponovitvama istega tona - medtem ko je večina uglasbenega nemškega besedila, vsaj v prvem delu, v akordsko oblikovanih blokih in hitrejši triglasni meri, v proportio sesquialtera in tripla ali pa tudi v t. i. "črnih notah". Ti deli so zborovski in blizu ritmični deklamaciji na nekaj tonih, medtem ko so latinski deli bolj razgibani, predvsem $\mathrm{v}$ smislu velikih skokov (oktavni skok v šestem glasu na besedo "laetamini «), ali pa melizmatično uglasbenih značilnih besed, npr. "vinum", pa bolj običajne "laeti" ali "laetati", v nemškem besedilu, pa proti koncu, ko se družba razživi na besedo "singt«. Nekateri glasovi občasno molčijo in nato zopet vstopajo, kar daje skladbi bolj razgibano in plastično dramaturgijo, ki pelje od vabila k družbi, hvalnici vinu in njegovim učinkom do dejanskega pitja in njegovega dokončnega učinka ("bis [...] schlaffen") ter na koncu budnice ("levate").

\footnotetext{
57 Prim. pesem Audientes audiant/diu schande uert al ueber daz laut iz tretjega dela obsežnega rokopisa, namenjenega prav pivskim, kockarskim in veseljaškim pesmim. Glej Carmina Burana [5. revidirana izdaja po izvirni kritični izdaji B. Bischoffa], München: Deutscher Taschenbuch Verlag, 1991, str. 636-638. V De Ducovem pivskem madrigalu je zaznavna tudi značilna metrična podoba teh pesmi. Več o tem v: Primož Simoniti, Spremna beseda, Carmina Burana, Ljubljana: Državna založba Slovenije, 1976, str. 81-93: 85.
} 


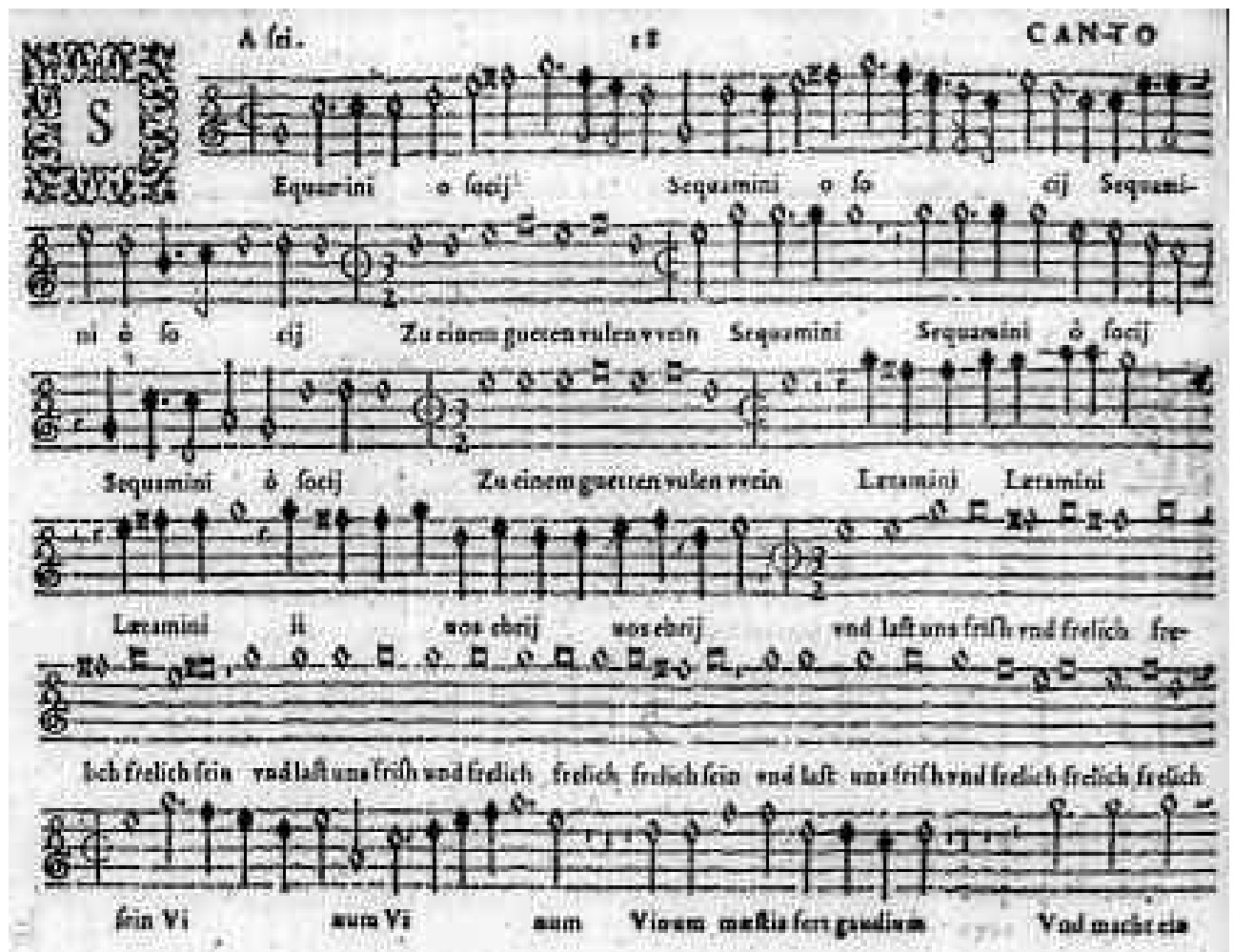

Slika 3: Začetek sopranskega glasu skladbe Sequamini o socii Filippa de Duca. (Po izvirniku iz Bayerische Staatsbibliothek v Münchnu: sig. 4 Mus.pr. 189, Beibd. 3, z dovoljenjem.)

De Duc te pesmi ni pomotoma uvrstil med svoje madrigale in nedvomno danes predstavlja dragocen namig na osebni in zelo prijateljski, morda skoraj družinski odnos med skladateljem in posvečenci, predvsem družino Khisl. Zato si poglejmo še, kdo so pravzaprav le-ti bili in koliko so se med seboj poznali.

Naj posežem najprej malo pred leto 1586, ko so bili madrigali De Ducove zbirke natisnjeni. Skladatelj, ki je, kot smo videli, v Padovi deloval vsaj od leta 1570, je prav v svojih prvih italijanskih letih tam lahko bolje osebno spoznal Jurija Khisla (med juriste se je vpisal decembra 1568) ${ }^{58}$ in Lenarta Merheriča (v Padovo je prišel kot preceptor dveh baronov Stubenberg s Štajerske), ${ }^{59}$ vsaj deloma pa se je seznanil tudi z očetom Janezom Khislom (ok. 1530-1593), ${ }^{60}$ ki je moral v času svojega obiska pri sinu vsaj malo spoznati tudi radoživo okolje študentske Padove in nekatere tam delujoče umetnike, morda vsaj katerega od padovanskih skladateljev, ki so prispevali svoja dela za antologijo triglasnih kanconet, ki jo je Angelo Barbato leta 1587 posvetil Janezovim trem mlajšim sinovom, ${ }^{61}$ ali pa Lodovica Balbija, kapelnika pri sv Antonu v Padovi, ki je pod okril-

\footnotetext{
58 Theodor Elze, Die Universität Tübingen und die Studenten aus Krain, München: Dr. Dr. Rudolf Trofenik, 1977, str. 67.

T. Elze, nav. delo, str. 66.

60 V virih in literaturi imenovan tudi Janž, Hans in Giovanni Khisl (tudi Kisel, Kis ali Chisel). O Janezu glej D. Pokorn, nav. delo, str. 450-451 in predvsem B. Zabota, nav. delo (2003), str. 10-14. Janez je potoval v Padovo leta 1570 skupaj s Herbertom Turjaškim, v času ko so tam študirali njuni sinovi. Podatek prinašata T. Elze, nav. delo, str. 21 in B. Žabota, nav. delo (2003), str. 11.

Glej op. 29, zgoraj.
} 
jem imena očeta Janeza Khisla (in imen vseh sinov) leta 1589 v Benetkah izdal zbirko Musicale essercitio. ${ }^{62}$

Janez Khisl je značilen povzpetnik, ki se je od vpisa med ljubljanske meščane leta 1551 skupaj z rastjo svojega premoženja tudi strmo vzpenjal po družbeni lestvici - leta 1569 je bil sprejet med viteze in 1590 je bil povzdignjen v baronski stan. Imel je zaupne in vplivne službe na nadvojvodskem dvoru v Gradcu, kjer je denar posojal celo samemu cesarju, kar je posredno povzročilo njegov finančni zlom proti koncu življenja. ${ }^{63}$ Sredi osemdesetih let je bil vsekakor med največjimi posestniki in najbogatejšimi Kranjci. Ker je imel očitno še posebno nagnjenje do raznih umetnosti, posebej pa do glasbe, ${ }^{64}$ seveda ni presenetljivo, da je bil pokrovitelj in zaščitnik številnih umetnikov, če ne drugače je izid njihovih del vsaj finančno podprl. ${ }^{65}$ Ne presenečajo nas seveda tudi ne njegovi dokumentirani stiki z italijanskimi glasbeniki v Gradcu. ${ }^{66}$

\section{Glasbena dela posvečena članom družine Khisl s Fužin pri Ljubljani}

- Giacomo GORZANIS, Intabolatura di liuto [...] Libro primo (Venetia, 1561): posvetilo Janezu

- Giacomo GORZANIS, Il Primo libro di Napolitane (Venetia, 1570): posvetilo Juriju

- Claudio MERULO, Il primo libro de ricercari da cantare a quattro voci (Venetia, 1574): posvetilo Juriju (na prvem mestu pa Wolfgangu Stubenbergu)

- Pietro Antonio BIANCO, Il primo libro de madrigali a quattro voci (Venetia, 1582): posvetilo Juriju

- Matthia FERRABOSCO, Canzonette a quattro voci. Libro primo (Venetia, 1585): posvetilo Janezu

- Filippo de DUC, Il Primo Libro de Madrigali a cinque et sei voci (Venetia, 1586): posvetilo Janezu Jakobu in Karlu (tudi Juriju in Vidu ter ostali druščini)

- Angelo BARBATO, Canzonette a tre voci. Libro primo (Venetia, 1587): posvetilo Vidu, Janezu Jakobu in Karlu

- Lodovico BALBI, Musicale essercitio [...] a cinque voci (Venetia, 1589): posvetilo Janezu in vsem štirim sinovom (Jurij, Vid, Janez Jakob in Karl)

- Romano MICHIELI, Musica vaga et artificiosa (Venetia, 1615): posvetilo Janezu Jakobu

62 Izvirna naslovnica se glasi: "MUSICALE ESSERCITIO DI LUDOVICO BALBI MAESTRO DI CAPELLA DEL SANTO DI PADOA A CINQUE VOCI In Venetia Appresso Angelo Gardano. M.D.LXXXIX." Na naslovnici je namesto tiskarjevega grafičnega znaka natisnjen Khislov grb, kar kaže na njegovo pomembnost, velik finančni prispevek k izdaji, ali pa kar na oboje. Posvetilo pa se naslavlja na "Al Molto Illustre Cavalliere Il Signor Giovanni Chisel da Coltemprun, et Gonobiz, etc. Hereditario Maestro di Caccia nel Ducato del Cragno, et della Marca Schiavona, et Scudiero supremo dell'Illustriss. Contado di Goritia Consigliero di sua Maestà Cesarea, Presidente della Camera Aulica del Sereniss. Arciduca Carlo d'Austria, et Capitano di Pistogna. Et allì molto Illustri Sig. Suoi Figlioli Gli Signori Giorgio, Guido, Gioan Giacomo, et Carlo Chiseli Da Coltemprun, et Gonouiz, etc. Hereditarij Maestri di Caccia nel Ducato del Cragno, et della Marca Schiavona, et scudieri supremi del l'Illustrissimo Contado di Goritia miei Signori Colendissimi."V antologiji so objavljeni lahki madrigali naslednjih skladateljev: J. Arcadelt, J. Berchem, I. Chamatero, G. A. Cardillo, G. Contino, F. Corteccia, B. Donato, A. Gabrieli, M. A. Ingegnerio, O. Lasso, B. Lupachino, L. Marenzio, T. Massaino, C. Merulo, P. de Monte, G. Nasco, A. Padovano, G. P. da Palestrina, B. Perisone, C. Porta, G. Rinaldi, C. de Rore, V. Ruffo, A. Striggio, P. Verdelot, G. Wert in A. Willaert. Izvirnik hrani Biblioteca Nazionale Marciana v Benetkah. Glej tudi E. Vogel [...], nav. delo, str. $125-126$.

63 Helfried Valentinitsch, Der innerösterreichische Hofkammerpräsident Hans Khisl von Kaltenbrunn (ca. 1530-1593). Einer frühkapitalischer Unternehmer zwischen protestantischen Ständen und katholischem Landesfürsten, Forschungen zur Geschichte des Alpen-Adria-Raumes, Festausgabe für em.o. Univ.-Prof. Dr. Otbmar Pickl zum 70. Geburtstag, ur. Herwig Ebner [...], Graz: Karl-Franzens-Universität Graz, 1997, str. 403-431.

64 Ferrabosco njegov odnos do glasbe v posvetilu zbirke štiriglasnih kanconet leta 1585 opisuje takole: "[...] sapendo io molto bene, quanto ella (oltre l'esser vero scudo di tutte le virtù) sia anco particolar amatrice, et prottetrice della Musica." Glej tudi op. 32, zgoraj.

65 O tem je pisalo že več avtorjev, tako zgodovinarjev kot tudi muzikologov, npr. Maja Žvanut, Barbara Žabota, pa Hellmut Federhofer, Danilo Pokorn in Alenka Bagarič. Prim. M. Žvanut, nav. delo, 1994, str. 158-169: 168; B. Žabota, nav. delo (2003), str. 13; Hellmut Federhofer, Musikpflege und Musiker am Grazer Habsburgerbof der Erzberzöge Karl und Ferdinand von Innerösterreich (1564-1619), Mainz: Schott, 1967, str. 238; D. Pokorn, nav. delo in Alenka Bagarič, Posvetila Giacoma Gorzanisa v knjigah glasbe za lutnjo (Benetke 1561, 1563, 1564), Muzikološke razprave. In memoriam Danilo Pokorn, ur. N. Cigoj Krstulović [...], Ljubljana: Založba ZRC, 2004, str. 15-26 (predvsem v zvezi s posvetili G. Gorzanisa).

66 Poleg posvetil graških glasbenikov naj omenim tudi Janezovo posredovanje leta 1590 glede zaposlitve Annibala Perinija, sicer člana nadvojvodove dvorne kapele, kot organista v protestantski šoli v štajerski prestolnici (to delo je opravljal do leta 1594). Italijanski glasbenik si je v tej vlogi očitno privoščil kar malo preveliko svobodo, za kar je bil deležen graje. leta 1593 se je inšpekcija pritožila, da se med bogoslužjem izvaja preveč italijanskih posvetnih pesmi, kot so fantazije, vilanele, madrigali in še kaj, celo plese. Hellmut Federhofer, Annibale Perini, Die Musikforschung 7 (1954), str. 402-414: 409, in Hellmut Federhofer, Die Musikpflege an der evangelischen Stiftskirche in Graz (1570-1599), Musik und Geschichte. Aufsätze aus nichtmusikalischen Zeitschriften, Hildesheim [...]: Olms, 1996, str. 225-262: 248. 
Če De Duc morda Janeza Khisla ni tako dobro poznal, saj se zdi njegovo posvetilo očetu bolj formalnega značaja v smislu vljudnostne poteze (oče je namreč tedaj drago plačeval študij treh mlajših sinov v Padovi in verjetno primaknil tudi kaj zlatnikov za De Ducov žep), pa je bil zagotovo dober prijatelj njegovih sinov. Jurij Khisl (tudi Georg, Giorgio; ok. 1555-1605) ${ }^{67}$ je bil pravi Kranjski velikaš, saj je od očeta po 1583 dobil veliko posesti, nekatere pa je tudi sam dokupil. V Padovo je očitno potoval še zelo mlad, saj se imenuje "mladi Jurij Khisl iz Ljubljane", koliko časa je tam ostal pa ostaja nejasno. Vsekakor je potem precej potoval, vse do Pariza. Njegov spremljajoči učitelj in varuh je bil Lenart Merherič, ki je bil v Padovi tudi preceptor barona Wolfganga Stubenberga (vpisal se je 2. aprila 1570). ${ }^{68}$ Wolfgangu Stubenbergu in Juriju Khislu je leta 1574 Claudio Merulo, takrat organist pri sv. Marku v Benetkah, posvetil svojo prvo knjigo štiriglasnih ricercarov, ${ }^{69}$ kar pa ni bilo prvo posvetilo kakega glasbenega dela družini Khisl. Že v prejšnjih štirih letih je bil Jurij naslovnik dveh beneških glasbenih tiskov, prve knjige vilanel Giacoma Gorzanisa in prve knjige štiriglasnih madrigalov Pietra Antonia Bianca. Jurij je bil vpisan na pravu skupaj s Samuelom Budino, sinom Lenarta Budine, rektorja ljubljanske stanovske šole, kar je nedvomno vplivalo na njegov odnos do književnosti in tudi glasbe. Samuel Budina se je leto prej, junija 1567 v Padovi vpisal tudi $\mathrm{k}$ artistom. ${ }^{70}$ Zanimivo je morda tudi to, da so Juriju Khislu posvečene prav vse izdaje prve slovenske glasbene pesmarice Eni psalmi, ki so jo med 1567 in 1595 kar petkrat natisnili. ${ }^{71}$ Za bolj izobražene protestantske kroge na Kranjskem in Štajerskem je bilo splošno znano, da so radi muzicirali in so gojili tudi posvetne glasbene zvrsti, o katerih katoliški viri molčijo.

Veliko manj je znanega o drugem Janezovem sinu, Vidu Khislu (tudi Veit, Guido; ?-1609). Opravljal je vojaško službo, v kateri je imel visoke položaje - leta 1601 je bil imenovan celo za polkovnika. Umrl je samski. ${ }^{72}$ Njegovo ime se omenja v treh posvetilih glasbenih del med 1586 in 1589 (De Duc, Barbato in Balbi), a v vseh nastopa le kot eden od treh ali štirih bratov Khisl. Tudi glede De Ducovega znanstva z družino ne predstavlja pomembnejšega elementa.

Vse kaže, da je bil glasbeno najbolj nadarjen in izobražen Janez Jakob Khisl (Johan Jacob, Giovanni Giacomo; 1565-1637), ki je, kot je bilo že rečeno zgoraj, izdal celo svojo lastno zbirko italijanskih madrigalov. Med drugim je bil leta 1615 edini posvečenec zbirke Musica vaga et artificiosa Romana Michiellija, ${ }^{73}$ sicer pa je med glavnimi pokrovitelji De Ducove, Barbatove in Balbijevih zbirk. Od vseh Janezovih sinov se je povzpel najvišje, saj je bil po spreobrnitvi h katoliški veri leta 1623 celo povzdignjen v grofovski stan - postal je grof Kočevski, prebival pa je večinoma v Gradcu, kjer je bil tudi dvakrat poročen. Njegova prva žena je bila Maria Thannhausen, verjetno sorodnica Doroteje, ki se je poročila z Georgom Hartmanom Stubenbergom, prav tako članom vesele padovanske druščine. ${ }^{74}$

\footnotetext{
7 Barbara Žabota, Družina Khisl v zgodnjem novem veku, Ljubljana: Filozofska fakulteta Univerze v Ljubljani (diplomska naloga), 2001 , str. 84-86.

68 I. Matschinegg, nav. delo, str. 582. Wolfgang Stubenberg je bil stric in pozneje varuh obeh v De Ducovem posvetilu imenovanih baronov Stubenberg.

69 Izvirna naslovnica se glasi: "IL PRIMO LIBRO DE RICERCARI DA CANTARE, A QUATTRO VOCI DI CLAUDIO MERULO DA CORREGGIO Organista in San Marco dell'Illustrissima Signoria di Venetia. Novamente composti et dati in Luce. CON PRIVILEGIO. LIBRO PRIMO In Venetia Appresso li Figliuoli di Antonio Gardano 1574. "Posvetilo pa se glasi "ILLUSTRIBUS WOLFGANGO BARONI A STUBMBERG, ET GEORGIO KHISL A KHALTEMPRUN. Adolescentibus non solum genere ac nobilitate Claris, sed etiam ingenio gratia, Naturae, Virtutisque bonis omnibus ornatissimis. CLAUDIUS MERULUS CORRIGGIENSIS.*

70 T. Elze, nav. delo, str. 65.

71 Trubarjevo izvirno posvetilo je bilo datirano v Derendingnu na Sv. Jurija 1667 in se glasi: "Dem Edlen und Ehrnuesten Junckern Georgen Kisel zum Khaltenbrun vund Rasbor Pfandthern zum Weichselburg etc." Enako posvetilo je bilo v ponatisu leta 1574 . Revidirana in razširjena izdaja iz leta 1684 ima predgovor Jurija Dalmatina, datiran 1. januarja v Wittenbergu in se naslavlja na "Georg Kisel zum Kaltenbrun und Gonouwitz Erblandjägermeister in Crain, unnd der Windischen Marck, auch Erbdrucksässen der Fürstlichen Graffschaft Görtz, Fürstliche etc. Regiments Rath etc." Posvetilo v ponatisu iz leta 1595 je podpisal Felicijan Trubar.

72 B. Žabota, nav. delo (2003), str. 17.

73 Izvirna naslovnica se glasi: "MUSICA VAGA ET ARTIFICIOSA Continente Motetti con oblighi, et Canoni diversi, tanto per quelli, che si dilettano sentire varie curiosita professare d'intendere diversi studii della Musica. DI D. ROMANO MICHIELI ROMANO. Novamente composta, et data in luce. IN VENETIA. APPRESSO GIACOMO VINCENTI. MDCXV " Na naslovnici je natisnjen Khislov grb.

74 O Janezu Jakobu glej B. Žabota, nav. delo (2003), str. 21.
} 
Karla Khisl (tudi Carlo; ?-1648) zgodovinska literatura skorajda ne pozna, ${ }^{75}$ očitno pa je bil dovolj priljubljen med glasbeniki, saj ga omenjajo tri posvetila. Filippo de Duc mu je skupaj z bratom Janezom Jakobom napisal celo posvetilni madrigal (gl. Prilogo 2). Skladatelj De Duc je torej od vseh Khislov najbolje poznal prav najmlajša brata, s katerima - in njuno družbo - je očitno večkrat veseljačil med njunim nekajletnim študijem v Padovi.

Kako resen je bil študij tujega plemstva v Padovi težko sklepamo, jasno pa je, da so se ob njem v osemdesetih letih tudi pošteno zabavali. ${ }^{76}$ Michel de Montaigne je v svojem popotnem dnevniku za november 1580 zgroženo zapisal, da je v Padovi videti, kot da mladež predvsem sablja, pleše in jaha, ter da je vzdušje na splošno zelo sproščeno in se dobro živi, kar je tudi razlog, da se tam zadržuje veliko tistih, ki niso več študentje. ${ }^{77}$ Sodeč po pismu dveh plemenitih Wurmbrandov, ki sta leta 1578 študirala v Padovi, materi, je bila na primer voda v Padovi tako zanič, da si takoj zbolel in zato mati prosita, da jima pošlje več denarja za vino, saj da je ceneje piti vino, kot plačati zdravnika (ko zboliš zaradi slabe vode). ${ }^{78}$ Torej ne preseneča, da je kot "hit" De Ducove prve knjige pet- in šestglasnih madrigalov objavljena prav hvalnica vinu.

Sicer pa, če je bilo potrebno še dodatno plačevati "zdravo“ pijačo, ne preseneča, da je bil študij v Padovi zelo drag, o čemer imamo na voljo več dokumentov. Med temi je še posebno zanimivo pismo, ki ga je Janez Khisl leta 1585 pisal grofu Wolfu Stubenbergu v zvezi z močno naraslimi stroški za študij njegovih nečakov in mladih varovancev Friedricha (ok. 1568-1620) ${ }^{79}$ in Georga Hartmanna (1563-1605) ${ }^{80}$ grofov Stubenberg, ${ }^{81}$ ki sta skupaj s Khislovima najmlajšima sinovoma med 1584 (Stubenberga sta se vpisala 1. junija) in 1588 (Stubenberga sta se septembra že vpisala tudi v Sieni in oktobra v Bologni) študirala v tem mestu. Janez tolaži Wolfa Stubenberga, da "se pri stroških ne da nič prihraniti. Gospodiča se morata tudi dobro imeti, njima je to lažje kot meni enakim [...] raje vidim, da se čim več naučita, kot da bi mi denar, ki ga porabita, ležal v skrinjii. ${ }^{82}$ Kako dober očka! Wolf Stubenberg je za štiri leta študija obeh nečakov odštel 5902 zlatnika in 27,5 kron, oče Khisl pa verjetno vsaj toliko, ali pa raje še malo več, ker je vsekakor kak cekin padel tudi v žep glasbenikov in skladateljev, ki so sinovom in ne nazadnje njemu samemu posvečali svoje umetnine. Tu je bila tudi plača preceptorja, ${ }^{83} \mathrm{ki}$ je skrbel za disciplino in študij varovancev. S Stubenbergoma in Kisloma je bil v Padovi Hijeoronim Megiser, ki je v De Ducovem posvetilu omenjen kot "najzvestejši učitelj», ki pa svojih gojencev očitno ni "odvračal" od dobre glasbene druščine.

V druščini, ki jo imenuje skladatelj, je bil tudi mladi baron Volkard Egk in Hungerspach, sin Jerneja, in Elizabete Klugel (poročena od 1564), gospoda s Smlednika pri Ljubljani. ${ }^{84}$ Ker je Elizabeta že po dveh letih umrla, ${ }^{85}$ se je moral Volkard roditi ok. 1565 ali 1566 . V času svojega bivanja, verjetno študija, v Padovi bi bil torej star okoli 17 let, s Khislovo družino pa se je moral poznati vsaj od poroke svojega strica Adama s sestro bratov Khisl Ano leta 1577. Volkard je ostal na Smledniku tudi po poroki s Katarino Tannhausen. Leta 1601 se je moral kot prepričani protestant s svojimi šestimi otroki odseliti, tako da je umrl leta 1609 v Regensburgu. ${ }^{86}$ Kaj več o Volkardu

B. Žabota, nav. delo (2003), str. 17.

76 Zgodovinarji na splošno ugotavljajo, da je bilo življenje študentov precej nenadzorovano ter da so živeli razpuščeno; večino časa so namenjali vinu, požrtijam in ženskam, kar De Ducova zbirka tudi nazorno dokazuje. M. Mugerli, nav. delo, str. 81-82. Glej tudi P. Del Piero, nav. delo.

77 Michel de Montaigne, Journal de voyage en Italie, Paris: Librarie Générale Française, 1974, str. 175-177, 181.

78 Odlomek iz pisma navaja I. Matschinegg, nav. delo, str. 72 , op. 80.

79 Podatek o rojstvu je priobčen po http://www.familysearch.org. Navaja tudi, da je bila mati Benigna von Scharffenberg ter da se je 1617 poročil z Anno Susanno Stubenberg.

80 Podatek je priobčen po http://www.familysearch.org. Navaja tudi, da je bila mati Benigna von Scharffenberg ter da se je 26 . maja 1595 poročil z baronico Dorotejo Thannhausen. Zadnja je bila sestra Katarine, žene Volkarda Egk in Hungerspacha.

81 Podatke o vpisi na univerzo je priobčila I. Matschinegg, nav. delo, str. 580, ki navaja tudi ime očeta - Johann.

82 Citat povzet po M. Žvanut, nav. delo, 1994, str. 63. Izvirni nemški odlomek, ki ga je prvi objavil A. Luschin-Ebengreuth, nav. delo, str. 3-60: 28, citira ga tudi I. Matschinegg, nav. delo, str. 72, op. 80. Izvirnik poimensko navaja oba mlada Stubenberga, ne pa tudi Khislovih sinov (samo "Söhne ). Sumim, da je M. Žvanut napačno sklepala, da je bil poleg Janeza Jakoba v Padovi Vid, saj je v matrikah zabeležen samo še Karl.

83 O tem več M. Žvanut, nav. delo, 1994, str. 63.

84 Majda Smole, Graščine na nekdanjem Kranjskem, Ljubljana: Državna založba Slovenije, 1982, str. 445

85 L. Slana, nav. delo, str. 41.

86 L. Slana, nav. delo, str. 53. 
ni znanega, razen morda notice, da se je njegov prijatelj baron Georg Hartman Stubenberg pozneje poročil z njegovo teto po materini strani, Dorotejo Tannhausen.

Glede na to, da je bil tudi pl. Gašper Gleispach, zadnji študent prava, ki ga v posvetilu omenja Filippo de Duc, doma s Štajerskega, lahko ugotovimo, da je bila druščina resnično mešana, saj so bili Khisli in Egk Kranjci, ostali pa so verjetno po vrnitvi s študija prispevali h glasbenemu utripu ali vsaj domačemu muziciranju v Gradcu in okoliških gradovih. Gašper Gleispach je bil sicer poklicni vojak in je preminil v neki bitki s Turki pri Kaniži. ${ }^{87}$ Med juriste v Padovi se je vpisal istega dne kot oba Stubenberga in verjetno so tudi potovali skupaj, kot je to zabeleženo za leto $1585 .{ }^{88} \mathrm{~V}$ Padovi so pred njim študirali tudi njegova starejša brata in oče. ${ }^{89}$

Ali je bil mentor mladega Gleispacha prav tako Hijeronim Megiser ni znano, je pa glede na to, da se v več dokumentih pojavlja skupaj s preceptorjevimi ostalimi varovanci, to več kot mogoče. Hijeronim Megiser (1554/55-1619) je predvsem znan kot protestantski jezikoslovec, literat in zgodovinar. ${ }^{90}$ Megiser je od leta 1571 študiral na univerzi v Tübingenu, kjer je spoznal več najpomembnejših slovenskih protestantov. Od leta 1582 je služboval na gradu Fužine pri Ljubljani kot domači učitelj mlajših sinov Janeza Khisla. Te je dve leti pozneje tudi spremljal v Padovo. Grad je takrat že pripadal starejšemu Juriju Khislu (Janez Khisl se je 1582 odselil v Gradec, na Fužinah pa naj bi stanoval Jurij in ostali sinovi pred odhodom v Padovo), ki mu je Megiser pozneje posvetil prvo izdajo svojega dela Paroemiologia Polyglottus (Gradec, 1592). Očitno je v Padovi ostal do konca študija svojih varovancev - poleg Khislov še vsaj obeh Stubenbergov - saj so ga leta 1588 nemški slušatelji prava izbrali za svojega prvega knjižničarja. V letih 1588-1589 je prepotoval vso Italijo. To pa ni bil zadnji stik Megiserja s Khislovimi, saj so se pozneje očitno družili tudi v Gradcu. Megiser je namreč 2. maja 1591 od tam poslal v Tübingen izvod na prav takrat tiskane izgubljene knjige madrigalov Janeza Jakoba Khisla, ki naj bi jo uporabili za izvedbo na univerzi. ${ }^{91}$

Zanimiv je morda podatek, da je bil v času Megiserjevega službovanja na Fužinskem gradu, zakupnik le-tega sicer upravitelj premoženja Janeza Khisla na Kranjskem, Lenart Merherič (Leonardo Mercheritsch; ?-po 1603), ${ }^{92}$ ki mu je De Duc leta 1586 naklonil svoj madrigal Non hai potuto in cotanti anni Amore. Merherič je bil očitno hrvaškega rodu, saj se v matrikah imenuje "Dalmata" ali "Illyricus“, znan pa je tudi kot sodelavec Konzula in Ungnada pri prevodu biblije v hrvaščino. Podobno kot v osemdesetih letih Megiser je bil tudi Merherič po zaključku študija v Tübingenu domači učitelj in mentor, prav tako Stubenbergom in Juriju Khislu, s katerimi je, kot smo že videli, bival v Padovi med 1567 in 1571 . Merherič je v letih 1582 in 1583 s knjigami iz Khislove fužinske knjižnice oskrboval rektorja Frischlina v Ljubljani, tako da sta se z Megiserjem nedvomno tudi osebno poznala. Bil je očitno zelo podjeten, saj se je hitro dvigal po družbeni lestvici in so ga leta 1587 že sprejeli med deželane. Pozneje je dal zgraditi grad Lesičje pri Zalogu. ${ }^{93}$ Morda je leta 1584 celo osebno spremljal mlade Khisle in Megiserja v Padovo, ali pa se ga je leta 1586 Filippo De Duc spomnil iz prejšnjih let.

Tega, ali so tudi na Kranjskem in Štajerskem kdaj slišali madrigale, ki jih je Filippo de Duc napisal za domače plemstvo, seveda ne vemo, je pa bila zbirka zabeležena tudi v inventarju ljubljanske stolnice: na fol. 5v najdemo citat "Madrig. Philippi de duce à 5“, v delu, ki ni bil več sis-

\footnotetext{
7 I. Matschinegg, nav. delo, str. 378. O Gašperju Gleispachu glej tudi op. 51, zgoraj.

88 Georg Hartman Stubenberg je, po podatkih, ki jih priobča Mascineggova, v Sieno leta 1585 potoval v družbi svojega brata Friderika, Gašperja Gleispacha ter Karla in Johanna Jakoba Khisla. I. Matschinegg, nav. delo, str. 580.

89 I. Matschinegg, nav. delo, str. 379.

90 Vsi podatki o Megiserju so povzeti po: Janez Logar, Megiser, Hijeronim, Slovenski biografski leksikon, ur. F. Kidrič in F. Lukman, zv. 2, Ljubljana: Slovenska akademija znanosti in umetnosti, 1933-1952, str. 84-87. Glej tudi T. Elze, nav. delo, str. 13.

91 O. Wessely, nav. delo, str. 400-401 in D. Pokorn, nav. delo, str. 457.

92 France Kidrič, Merherič (Mercheritsch, Mercharitsch) Lenart, Slovenski biografski leksikon, ur. I. Cankar [...], zv. 1, Ljubljana: Slovenska akademija znanosti in umetnosti, 1925, str. 95-96; T. Elze, nav. delo, str. 66-67 in B. Žabota, nav. delo (2003), str. 11-12.

93 M. Smole, nav. delo, str. 257.
} 
tematično urejen po zvrsteh. ${ }^{94}$ Ker so bili vsi naslovljenci De Ducovih posvetil očitno dobri prijatelji in, kot smo videli, tudi družinsko povezani, lahko sklepamo, da se se tudi po letu 1588 kdaj sestali in skupaj muzicirali.

Posvetila zgoraj omenjenim plemičem vsekakor pomenijo, da so bili glasbi naklonjeni in vsaj odlični amaterski glasbeniki, ki so tedaj najsodobnejšo italijansko posvetno glasbo nedvomno gojili tudi na svojih domovih, pa naj je bilo to na Štajerskem ali pa na kranjskem Smledniku, Lesičjem, predvsem pa čudovitem renesančnem Fužinskem gradu. O tem ne nazadnje pričajo tudi dokumenti, ki govorijo o prisotnosti glasbil in glasbenih tiskov oz. rokopisov po gradovih konec 16. stoletja. Tako sta zabeleženi dve tabulaturi za lutnjo v knjižnici Franca Galla, dve rokopisni tabulaturi, neka šestglasna skladba in klavikord pri Francu Rainu v Ljubljani, pa virginal pri Wolfgangu Engelbertu Auerspergu in spinet pri Bittorferjevih itd. ${ }^{95}$

Žal se je v obliki materialnih glasbenih ostankov (glasbenih tiskov ali rokopisov) ohranil le drobec tistega, kar so sodeč po sekundarnih zgodovinskih virih, kot so inventarji (tisti že omenjeni in slavni, v katerem je dal v dvajsetih letih 17. stoletja Tomaž Hren popisati glasbena dela v ljubljanski stolnici, a kot smo videli tudi vrsta manj znanih plemiških zapuščinskih inventarjev, pa opombe o obsežni Bohoričevi knjižnici, ${ }^{96}$ vrsta ohranjenih pisem, raznih uradnih zapiskov, predvsem pa posvetil glasbenih del domačemu plemstvu, pričajo o razvitemu glasbenemu življenju.

\section{Priloga 1: Transkripcija posvetila Janezu Jakobu in Karlu Khisl ter njuni druščini ${ }^{77}$}

ALLI MOLTO ILLUSTRI SIGNORI, LI SIGNORI GIO: GIACOMO ET CARLO CHISELI da Caltenprun et Gonobiz, etc. Hereditarii Maestri di Caccia del Ducato di Cragno, et della Marca Schiavona, et Scudieri dell'Illustriss. Contado di Goritia, Padroni miei Colendissimi.

Accade à un libro nuovo, quell'istesso quasi, che suol'occorrer' à un tempio nuovo: atteso, che il tempio, quantonque sia fabricato con architettura ingeniosissima, et con pietre preciosissime, con tutto ciò, se non è consecrato à un Spirito divino et celeste, già mai sarà con tanta copia de popoli riverito et celebrato. Le onde bramoso et desideroso io, che queste mie fatiche Musicali, da Spiriti svegliati et virtuosi siano vedute et riverite, son caduto in pensiero di publicarle sotto l'illustre, et celebratissimo nome delle Signorie VV. et anco, per esser loro fuor di modo amatori, et fautori delle virtù, et specialmente della Musica: si come ancora è l'Illustre Signor suo Padre, benemerito Cavaliero, et Consigliero di S.M. Ces. et Presidente della Camera Aulica del Serenissimo Arciduca Carlo, et li fratelli delle VV. cioè, l'Illustre Signor Giorgio et Signor Guido. Et dì ciò certo me n'hanno fatto palese i continui essercitii virtuosi, si con le SS. VV. fatti come anche con la honoratissima compagnia vostra, cioè de gli Illustri S S Federico, Gior: Artmano fratelli Baroni da Stubenberg, et del Signor Volcardo Barone da Egk et Hungerspach, et del Signor Gasparo da Glaispach, tutti miei Signori osservandissimi, insieme co'l vostro fedelissimo Governatore, il Signor Girolamo Megisero, à quali priegho da Iddio ogni bene, et con grandissima humiltà faccio profonda riverenza.

Di Padova il dì 15. di Genaro 1586.

Delle SS. VV. molto Illustri, Fidelissimo Servitore, Filippo de Duc Fiamengo.

94 J. Höfler, nav. delo, 1978, str. 152-153. Zelo verjetno gre prav za zbirko iz leta 1586, saj je edina znana, ki vsebuje petglasne madrigale. Večina drugih del, navedenih na isti strani seznama, je poznejših in so tako duhovnega kot tudi posvetnega značaja. Morda je šlo za kake pridobitve iz zaplenjenega premoženja oz. knjižnic protestantskih plemičev, ali pa zbirka sodi celo med možne pridobitve iz Gradca. Prim. Metoda Kokole, Zgodnja duhovna monodija v notranjeavstrijskih deželah in prispevek Isaaca Poscha, Muzikološke razprave. In memoriam Danilo Pokorn, ur. N. Cigoj Krstulović [...], Ljubljana: Založba ZRC, 2004, str. 27-44: 30-31.

95 M. Žvanut, nav. delo, 1994, str. 154.

96 A. Rijavec, nav. delo, str. $139-142$.

97 Transkripcija avtorice v posodobljeni pisavi je objavljena po izvirniku, ki ga hrani Bayerische Staatsbibliothek v Münchnu pod signaturo 4 Mus.pr. 189, Beibd. 3, z dovoljenjem. 


\section{Priloga 2: Posvetilni madrigal bratoma Janezu Jakobu in Karlu Khisl ${ }^{18}$}

\section{Giovan Giacomo et Carlo}

Filippo de Duc (1586)
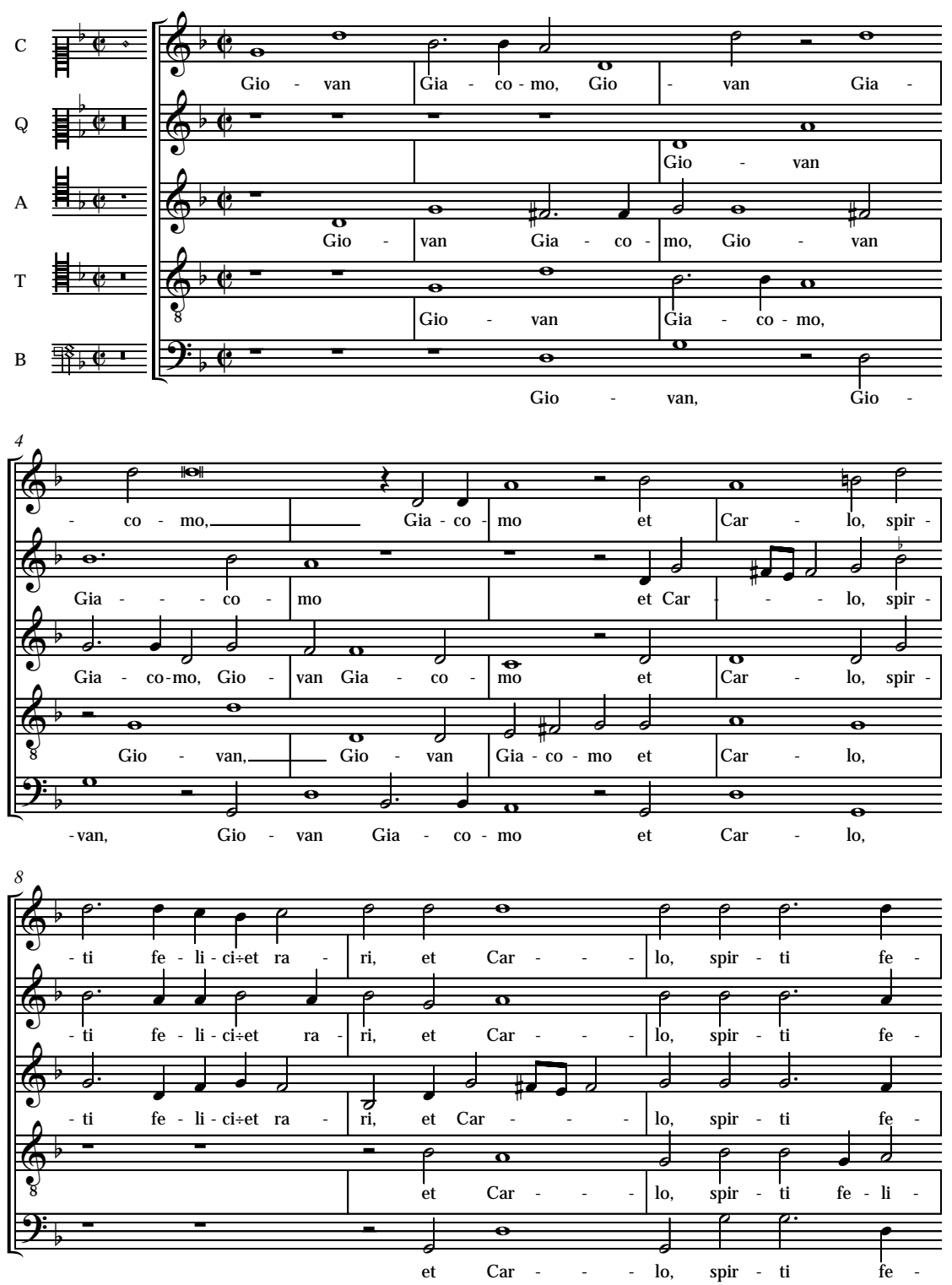

8 Transkripcija avtorice je objavljena po izvirniku, ki ga hrani Bayerische Staatsbibliothek v Münchnu pod signaturo 4 Mus.pr. 189, Beibd. 3, z dovoljenjem. 

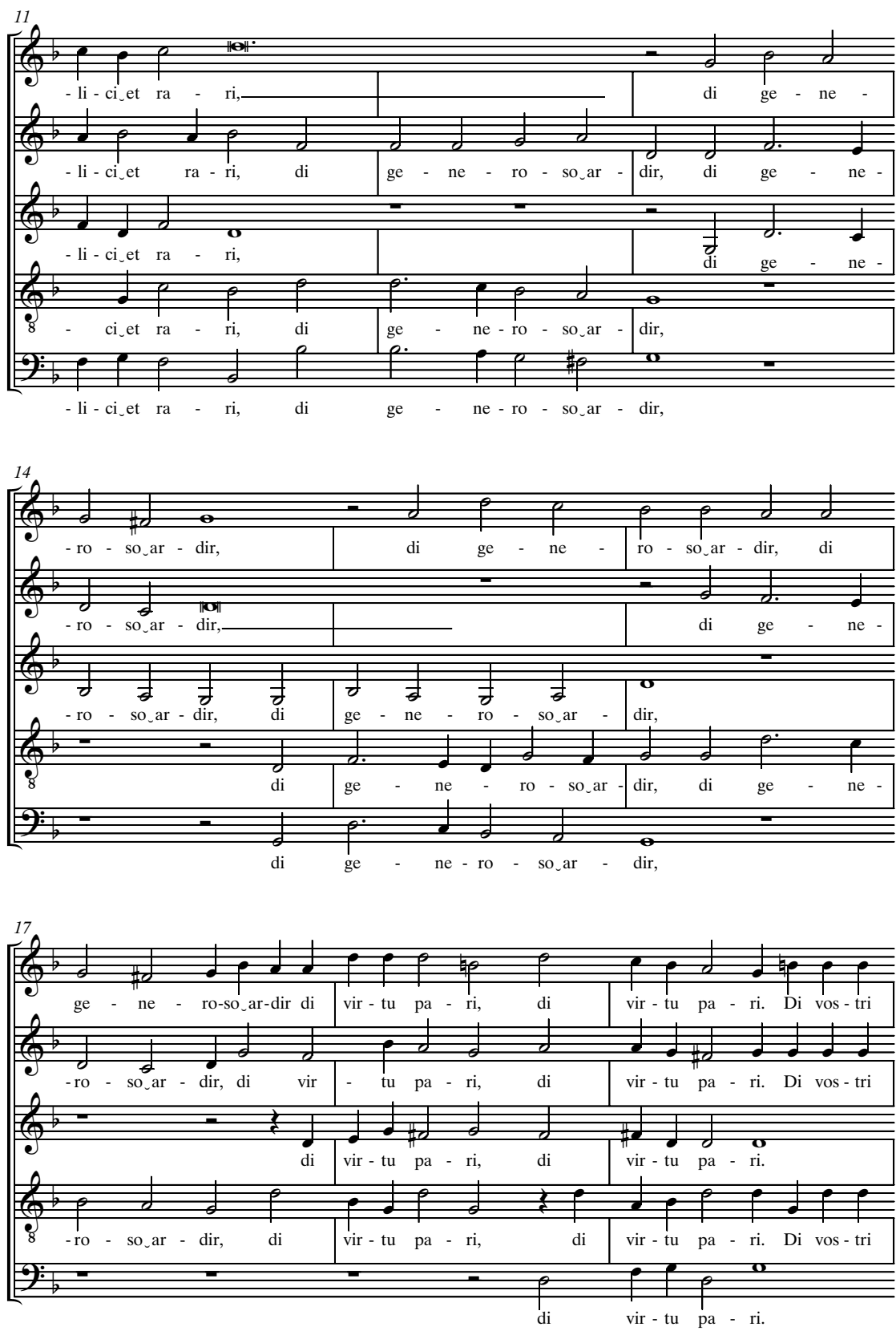

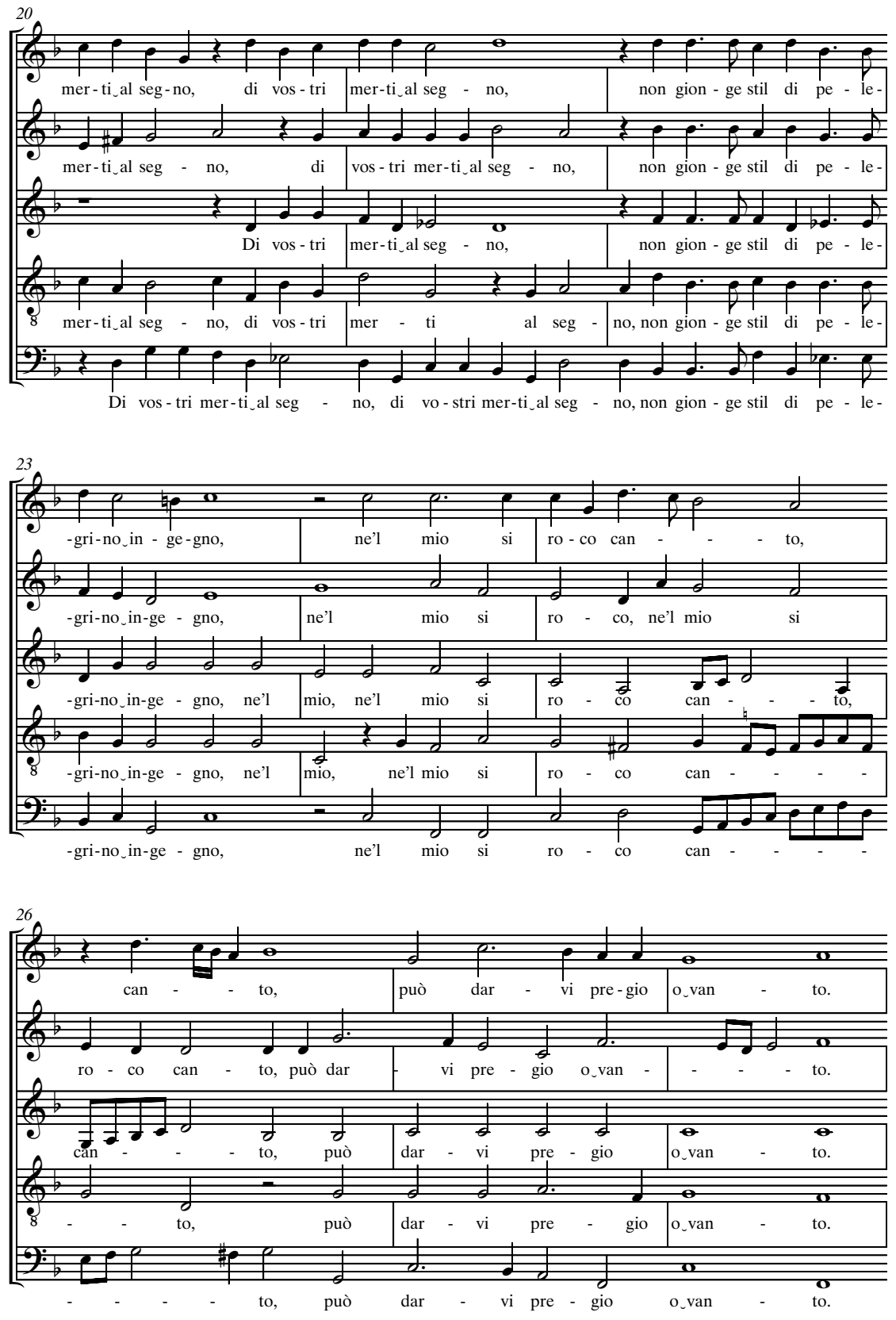

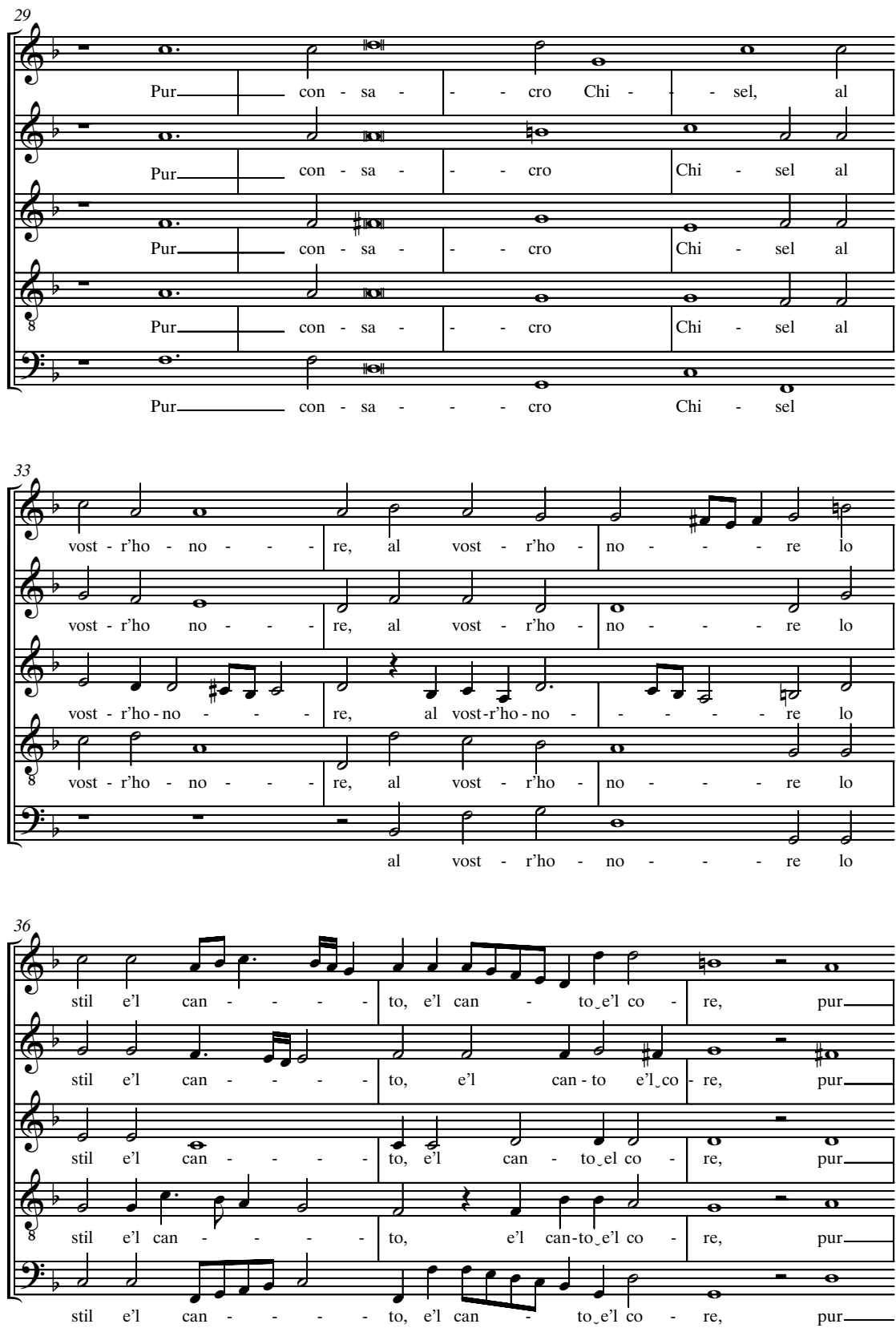

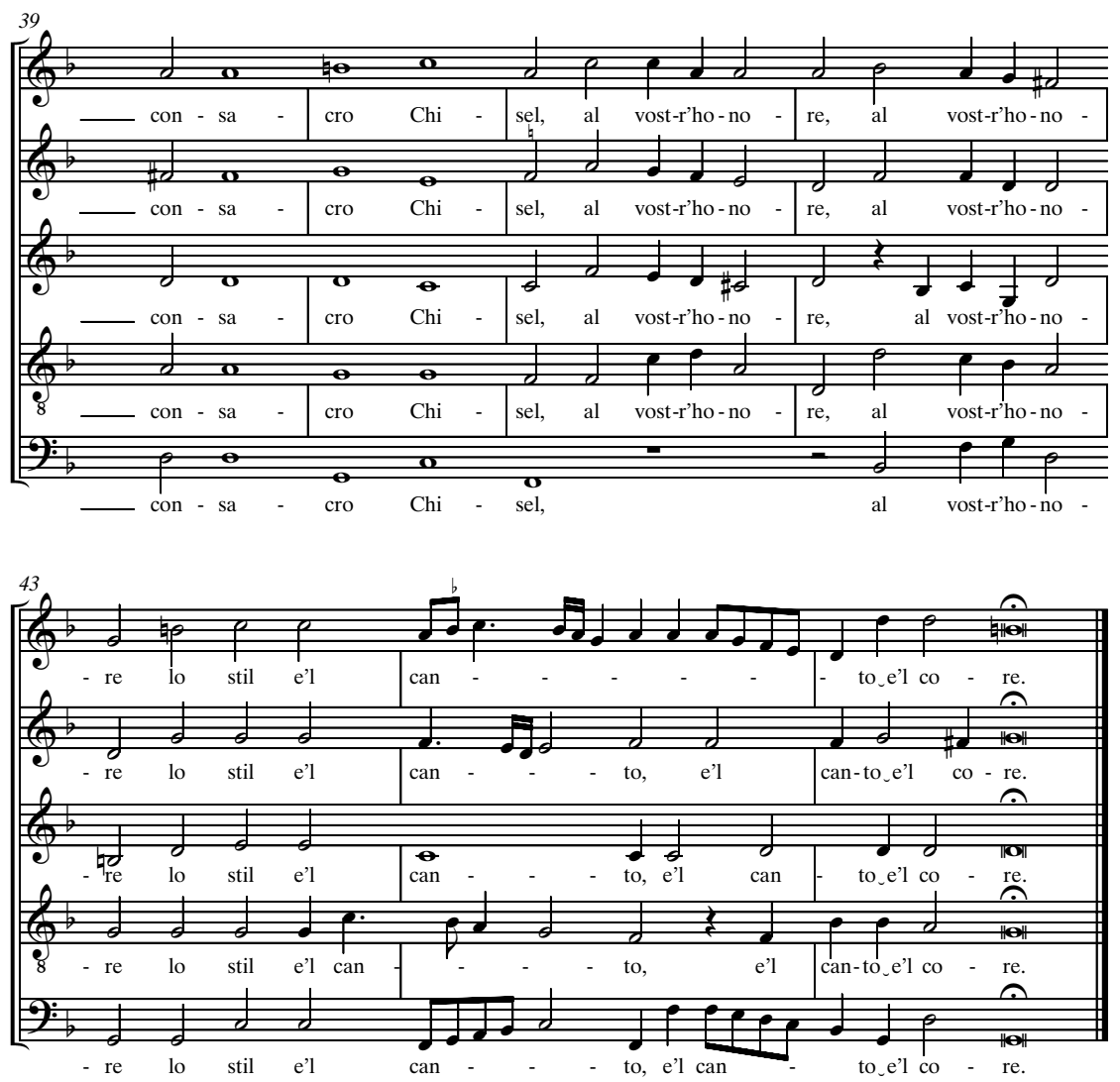

\section{SUMMARY}

Very little is known of the movements of the Flemish composer Philippe de Duc - a boysinger at the Imperial chapel in Vienna and later a musician and composer active in Padua, where he was known as Filippo de Duc - between around 1570 and 1586. He possibly acted in Padua as a private teacher of university students. Three books of mostly secular music, all printed in Venice, have survived. The last, Il primo libro de madrigali a cinque et sei voci, printed in 1586 by the Venetian publishing house of Giovanni Vincenti and Ricciardo Amadino, is preceded by a most interesting dedicatory letter, containing many names of considerable importance for the local cultural history of Carniola and Styria, which were then Inner-Austrian provinces but today belong to Slovenia and Austria. De Duc's collection of thirteen madrigals, dated Padua, 15 January 1586, is dedicated primarily to the brothers Giovanni Giacomo and Carlo Khisl, law students at the university of Padua who were members of a leading noble family in Carniola, whose main seat at the time was the castle of Kaltenbrunn (Fužine) near Ljubljana. The Khisls, especially the father Hans and his eldest son Georg, both similarly named in the dedication, were fervent supporters of the Reformation; even more, they were known as leading patrons of mu- 
sic in the Inner-Austrian lands who took a special interest in contemporary Italian secular music. Nine printed collections of Italian light vocal and instrumental music were dedicated to different members of this family between 1561 and 1615, some of them by well known composers (including Giacomo Gorzanis, Pietro Antonio Bianco and Claudio Merulo). The first dedicatee of De Duc's collection, Giovanni Giacomo, was apparently musically the most talented, and even tried his hand at composition. Unfortunately, Giovanni Giacomo Khisl's Il primo libro de madrigali et motetti a 4 et 5 voci, printed by Ricciardo Amadino in Venice in 1591, is now lost. Moreover, De Duc's letter of dedication reveals other Carniolan connections, since in it the composer addresses himself in addition, as already mentioned, to the father, Hans, and to two older brothers, Georg and Veit, as well as to the whole "illustrious company" comprising the brothers Friedrich and Georg Hartmann, Counts of Stubenberg, Baron Volk of Egk and Hungerspach, and Kaspar of Gleispach (all members of staunchly Protestant families in Carniola and in Styria, linked also by inter-family marriages), together with the Khisl family's private tutor Hieronimus Megiser (1554/55-1619), a famous humanist, linguist and historian. However, not only is the collection as a whole dedicated to the Khisl family, but it also contains two individually dedicated pieces. The first of these is a madrigal in honour of the same two brothers, Giovan Giacomo et Carlo, spirti felici et rari (analysed into some detail as the core piece of the collection and transcribed in appendix 2), while the tenth piece of the collection, Non hai potuto in cotanti anni Amore, is a tripartite madrigal for five voices dedicated to another well-known person, Leonard Mercheritsch ("Al sign. Leonardo Mercherich"; in Slovenian, also Lenart Merherič), who was another relatively prominent Protestant writer active, variously, in Tübingen and Carniola. He is known to have been a private tutor to Georg Khisl and to two sons of the Styrian nobleman Stubenberg, all of whom studied in Padua from 1567 to 1570 . He possibly accompanied the younger Khisl brothers to Padua in 1584 (they remained there together with their tutor Megiser till 1588), or perhaps he was known to De Duc from earlier contact. An attempt has been made to interpret also the madrigal Anna bella gentil cortes' et saggia as a specific dedicatory piece - in praise of the sister of the two main dedicatees, Ana Khisl (married in 1577 to Baron Volk Egk and Hungerspach), who was known as a beautiful, gentle, faithful, pious (etc.) woman. The madrigals of Filippo de Duc's 1586 collection reflect musically the then current hybrid style, marked by the inclusion of elements typical of lighter secular genres. A salient example of such a piece is the concluding madrigal Sapete voi qual sia, labelled Alla Napolitana, which contains a hidden refrain. The texts vary from the extremely belletristic (one of the pieces is composed on a section of a poem by Petrarch and another on Tasso's verses) to a rather vulgar half-Latin, halfGerman drinking song, Sequamini ò socii. Zu einem guten vulen wein. The latter piece is a rather interesting composition in the tradition of Goliardic Carmina Burana, such as were sung by merry students in Padua and elsewhere - a genre that otherwise rarely found its way into print. All the dedications and the contents of the entire collection furnish eloquent testimony to the popularity of Italian secular music among the Protestant upper classes in the Inner-Austrian lands, and to the genre's migration from Northern Italy to the German-speaking lands. 